\title{
Método de búsqueda eficiente para resolver el problema de identificación de huella dactilar aplicando machine learning
}

María Elena Ruiz Rivera EDGAR RUIZ LIZAMA ${ }^{2}$

\begin{abstract}
RESUMEN
En tecnología biométrica, el problema de identificación de huella dactilar ha sido ampliamente estudiado en las últimas décadas debido a su aplicabilidad en casos de identificación de personas. En casos de siniestralidad, se requiere el reconocimiento de la persona afectada, lo cual debe realizarse de manera inequívoca mediante la identificación dactilar. El objetivo de la presente investigación es innovar el proceso de identificación de huella dactilar a través de un método de búsqueda eficiente en una gran base de datos que permite encontrar una huella dactilar en menor tiempo mediante la clasificación de las huellas dactilares en segmentos, según sus características más próximas, utilizando machine learning; luego, en un determinado segmento, se aplica el algoritmo discreto de búsqueda secuencial, con el que se ubica la huella dactilar requerida.
\end{abstract}

Palabras clave: Huella dactilar; biométrico; aprendizaje automático; búsqueda de huella dactilar.

\section{INTRODUCCIÓN}

Debido al incremento de la tecnología respecto a la comunicación y transferencia de datos a través de redes, el uso sistemas de huellas dactilares se ha hecho común en el área forense y policial, tanto en instituciones del Estado como en instituciones privadas. Un ejemplo de ello son los bancos, donde se verifica la huella para realizar retiros de dinero, lo que brinda seguridad al cliente ante una suplantación o robo de identidad. Otro caso es cuando un delincuente ingresa a la sala de operaciones con el fin de practicarse varias cirugías estéticas para lograr un cambio físico notorio de su persona; la identidad de esta persona se detecta gracias a su huella dactilar, que es única e irrepetible. De la misma forma, cuando se presenta una persona desfigurada por algún accidente, se puede realizar su reconocimiento inequívoco gracias a sus huellas dactilares.

La investigación se basa en la búsqueda de información en grandes bases de datos, lo que origina que el tiempo de respuesta se vea reflejado en costos muy elevados; así, la búsqueda de imágenes complica aún más el levantamiento de información. El almacenamiento de una imagen digital implica contar con un gran espacio de memoria, y si se trata de una gran cantidad de imágenes, se eleva el costo. La búsqueda de este tipo de información se puede realizar utilizando diferentes tipos de algoritmos; sin embargo, se debe tener en cuenta el tiempo de respuesta y el costo que se originan al realizar la búsqueda en estas grandes bases de datos, donde el tiempo de respuesta es fundamental.

La búsqueda eficiente de huellas dactilares conduce al objetivo general de investigación, que es plantear un método de búsqueda eficiente de huella dactilar a un menor costo y tiempo, en

1 Licenciada en Computación por la Universidad Nacional Mayor de San Marcos (Lima, Perú). Actualmente, es docente de la Facultad de Ingeniería de Sistemas e Informática en la Universidad Nacional Mayor de San Marcos.

ORCID: https://orcid.org/0000-0003-3300-7068

Autor de correspondencia: mruizr@unmsm.edu.pe

2 Ingeniero industrial por la Universidad Nacional Mayor de San Marcos y Magíster en Informática por la Pontificia Universidad Católica del Perú (Lima, Perú). Actualmente, es docente de la Facultad de Ingeniería Industrial de la Universidad Nacional Mayor de San Marcos.

ORCID: https://orcid.org/0000-0001-9403-1358

E-mail: eruizl@unmsm.edu.pe 
el cual se aplica machine learning, para la clasificación de segmentos, y algoritmo discreto, para la búsqueda secuencial en un determinado segmento.

Realizar una búsqueda secuencial en una gran base de datos genera demora en el tiempo de búsqueda. Las huellas dactilares cuentan con características que permiten su clasificación, como arco, arco derecho, arco izquierdo, arco de carpa y circular o espiral (Dass y Jain, 2004). El trabajo de búsqueda de huellas dactilares presentado se enfoca únicamente en huellas dactilares de individuos en una macro base de datos con la finalidad de reducir el tiempo de búsqueda.

La clasificación de huellas dactilares consiste en realizar un particionamiento sistemático de la base de datos en diferentes segmentos utilizando machine learning. Dichos segmentos se conforman por la aproximación de las características de cada huella dactilar. La clasificación de las huellas en segmentos reduce significativamente el tiempo empleado en la identificación de las huellas dactilares, especialmente en situaciones donde la precisión y la velocidad son críticos.

La propuesta del método consiste primero en clasificar las huellas dactilares por sus características utilizando machine learning, de modo que sea posible crear grupos por características similares o más próximas; luego, en un segundo momento, utilizar un algoritmo discreto que permita realizar una búsqueda secuencial y encontrar la huella buscada.

\section{MARCO TEÓRICO}

\section{Sistemas biométricos}

Un sistema biométrico esencialmente es un reconocedor de patrones que captura datos biométricos de una persona, extrae un conjunto de características a partir de dichos datos y las compara con otros patrones previamente almacenados en el sistema (Wayman, Lain, Maltoni, y Maio, 2005).

Un sistema biométrico es un sistema automatizado que realiza tareas de biometría. Es decir, es un sistema que fundamenta sus decisiones de reconocimiento mediante las características físicas o de comportamiento de una persona de manera automatizada ( Fernández, 2008).

Para solucionar estos problemas, se vienen desarrollando métodos basados en ciertos rasgos biométricos que garantizan la identidad de las personas. Estos rasgos biométricos están clasificados en dos tipos (Fernández, 2008): El primero es la biometría fisiológica, basada en las partes de cuerpo, como son las huellas dactilares, el iris, la retina, la voz, la mano y el rostro. El segundo tipo es la biometría conductual, basada en las de acciones de una persona, como, por ejemplo, la firma de un individuo.

\section{Características de un indicador biométrico}

Según Fernández (2008), un indicador biométrico es alguna característica con la cual se puede realizar biometría, así se tiene:

- Universalidad: el rasgo biométrico existe para todas las personas.

- Unicidad: el rasgo identifica unívocamente a cada persona.

- Permanencia: el rasgo se mantiene invariable con el tiempo a corto plazo.

- Inmutabilidad: el rasgo se mantiene invariable con el tiempo a largo plazo o durante toda la vida.

- Mensurabilidad: el rasgo es apto para ser caracterizado cuantitativamente.

- Rendimiento: el rasgo permite el reconocimiento del individuo con rapidez, robustez y precisión.

- Aceptabilidad: el rasgo debe ser aceptado por la mayoría de la población.

- Invulnerabilidad: el rasgo permite la robustez del sistema frente a los métodos de acceso fraudulentos.

La Tabla 1 muestra las diversas tecnologías biométricas según los grados de confianza (alto, medio, bajo) de las propiedades anteriormente descritas (Maltoni, Maio, Jain, y Prabhakar, 2003).

\section{Identificación biométrica}

La identificación biométrica ha sido definida por el profesor Jain Lakhmi como el proceso que permite relacionar de forma automática la identidad de un individuo mediante el uso de algunas características físicas o del comportamiento que sea inherente a la persona (Fernández, 2008).

\section{Huella dactilar}

Una huella dactilar es la representación de la morfología superficial de la epidermis de un dedo (Persto, 2020). La huella dactilar se forma en la etapa fetal del ser humano y está constituida por crestas papilares; asimismo, es inmutable durante toda la vida, 
a menos que sufra lesiones o daños severos (Villamizar, 1994).

\section{Características de la huella dactilar}

En 1892, Francis Galton publicó el primer sistema de clasificación y estableció la individualidad y permanencia de las huellas dactilares; los "puntos finos" que Galton identificó son utilizados hoy en día (Persto, 2020).

Dass y Jain (2004) se basaron en la clasificación de las huellas digitales de Henry (1900), quien plantea cinco clases principales basadas en el NIST4: (a) arco izquierdo, (b) arco derecho, (c) arco, (d) arco de carpa y (e) circular o espiral. Esta se muestra en la Figura 1.

\section{El módulo de inscripción o almacenamiento de la Huella dactilar}

Se encarga de la adquisición análoga o digital de algún indicador biométrico de una persona, como, por ejemplo, la adquisición de la imagen de una huella dactilar mediante un escáner. Una vez obtenida la huella se almacena en la base de datos

Tabla 1. Comparación de tecnologías biométricas.

\begin{tabular}{lccccccc}
\hline $\begin{array}{l}\text { Identificador } \\
\text { biométrico }\end{array}$ & Universalidad & Unicidad & Permanencia & Mensurabilidad & Rendimiento & Aceptabilidad & Invulnerabilidad \\
\hline ADN & Alto & Alto & Alto & Bajo & Alto & Bajo & Bajo \\
Oreja & Medio & Medio & Alto & Medio & Medio & Alto & Medio \\
$\begin{array}{l}\text { Cara } \\
\text { Termo grama }\end{array}$ & Alto & Bajo & Medio & Alto & Bajo & Alto & Alto \\
facial & Alto & Alto & Bajo & Alto & Medio & Alto & Bajo \\
Huella dactilar & Medio & Alto & Alto & Medio & Alto & Medio & Medio \\
Modo de andar & Medio & Bajo & Bajo & Alto & Bajo & Alto & Medio \\
Geometría de & Medio & Medio & Medio & Alto & Medio & Medio & Medio \\
la mano & Medio & Medio & Medio & Medio & Medio & Medio & Bajo \\
mano & Alto & Alto & Alto & Medio & Alto & Bajo & Bajo \\
Iris & Bajo & Bajo & Bajo & Medio & Bajo & Medio & Medio \\
$\begin{array}{l}\text { Pulsación de } \\
\text { teclado }\end{array}$ & Alto & Alto & Alto & Bajo & Bajo & Medio & Bajo \\
Olor & Alto & Alto & Medio & Bajo & Alto & Bajo & Bajo \\
Retina & Bajo & Bajo & Bajo & Alto & Bajo & Alto & Alto \\
Firma & Medio & Bajo & Bajo & Medio & Bajo & Alto & Alto \\
Voz & Majo & Majo &
\end{tabular}

Fuente: Datos basados en la percepción de los autores del libro Handbook of Fingerprint (Maltoni et al., 2003).

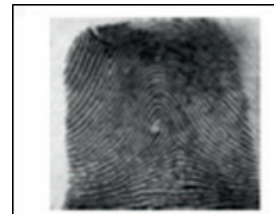

(a)

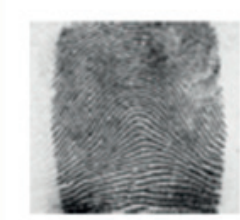

(c)

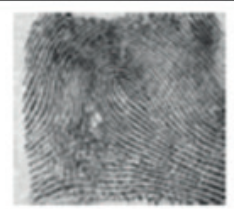

(b)

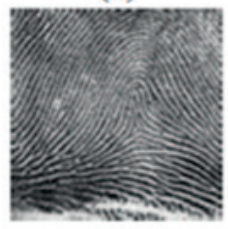

(d)

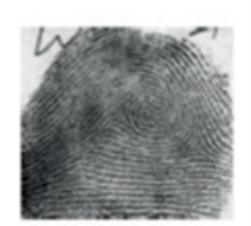

(e)

Figura 1. Clasificación de las huellas digitales.

Fuente: Base de datos especial del Instituto Nacional de Estándares y Tecnología (NIST4) (Dass y Jain, 2004) 
(patrones o plantillas) proveniente de un dispositivo biométrico. El proceso se puede observar en la Figura 2.

\section{Arquitectura de los procesos de un sistema biométrico}

El proceso actual inicia en el ingreso de la huella dactilar en un aparato de reconocimiento de huella con un escáner óptico de huellas. Este aparato convierte la información en dígitos y captura la imagen de la huella ingresada. Una vez digitalizada, la huella es llevada a la base de datos (plantilla) por medio de algoritmos matemáticos según su característica particular.

Luego se continúa con la captura en vivo de la huella que se va a buscar; extrayendo sus características se realiza la búsqueda en la base de datos donde se encuentran almacenadas con anterioridad las huellas. Si encuentra coincidencias con la imagen ingresada, se puede comprobar la identidad de la persona a quien corresponde dicha imagen, lo que da un resultado positivo en la búsqueda. Si se diera el caso de no encontrar coincidencias en la imagen digitalizada de la huella, esta es comparada y arroja un resultado negativo de dicha búsqueda (ver Figura 3).

\section{Método de clustering}

El clustering tiene aplicaciones variadas dentro de las ciencias de la computación, como, por ejemplo, la compresión de imágenes (Scheunders, 1997) y digitalización de la voz (Makhoul, Roucos y Gish, 1985); recuperación de información relacionada (Bathia y Deogun, 1998); minería de datos, donde se da la búsqueda de grupos con determinadas características de interés (así se tiene el descubrimiento de nuevos segmentos de clientes con el objetivo de mejorar los servicios que se brinda) (Fayyad, Piatetsky-Shapiro y Padhraic, 1996); la segmentación de imágenes al dividir la imagen en regiones homogéneas (de acuerdo con alguna característica de interés como son la intensidad, el color o textura), esto es especialmente importante en aplicaciones médicas (Pham y Prince, 1999); y la clasificación de imágenes satelitales en diferentes zonas (urbana, descampados, ríos, bosques) (Soldberg, Taxt, y Jain, 1996).

Los métodos de clustering se diferencian entre ellos en la manera de componer los clusters. Aquellos que lo hacen según la correspondencia a una partición del conjunto de objetos son conocidos como métodos de Hard-clustering (Kearns, Mansour, y $\mathrm{Ng}, 1997$ ); de estos, el más conocido es el algoritmo K-Means (Forgy, 1965; MacQueen, 1967).

\section{Algoritmo K-Means}

El algoritmo K-Means aplicado a clustering (Forgy, 1965) es una heurística comúnmente utilizada para resolver el problema de clustering (MacQueen, 1967). La idea esencial del algoritmo es tener los $\mathrm{K}$ centros iniciales y armar clusters asociando los objetos de $\mathrm{X}$ a los centros más cercanos; luego, se recalculan los centros. Si los nuevos centros no difieren de los centros previos, el algoritmo finaliza; en caso contrario, se itera el proceso de asociación con nuevos centros hasta que no exista variación en los centros o se establezca algún nuevo criterio de parada con poco número de reasignaciones de los objetos para estos métodos.

\section{Machine learning}

Se denomina machine learning a un conjunto de algoritmos computacionales que comparten un

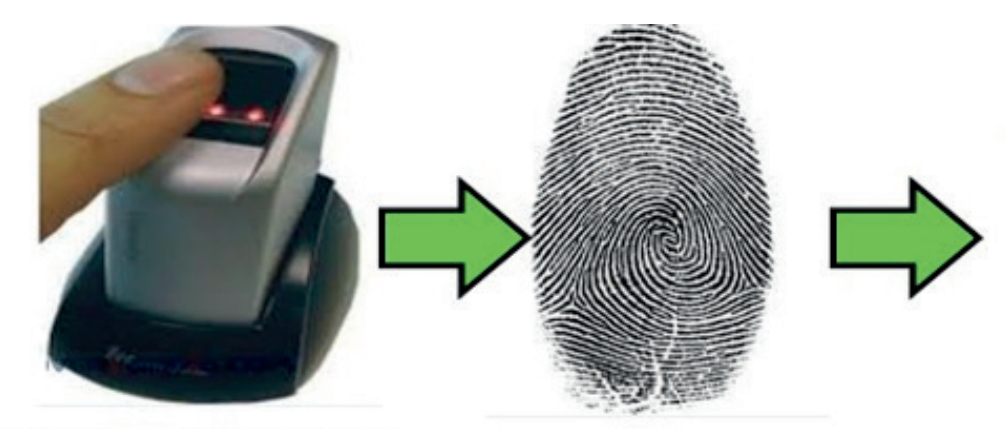

SENSOR BIOMÉTRICO
HUELLA DACTILAR

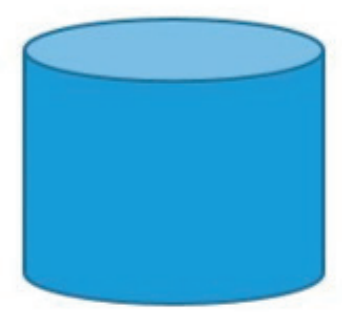

BASE DE DATOS

Figura 2. Módulo de inscripción de una huella dactilar de un sistema biométrico.

Fuente: Elaboración propia. 


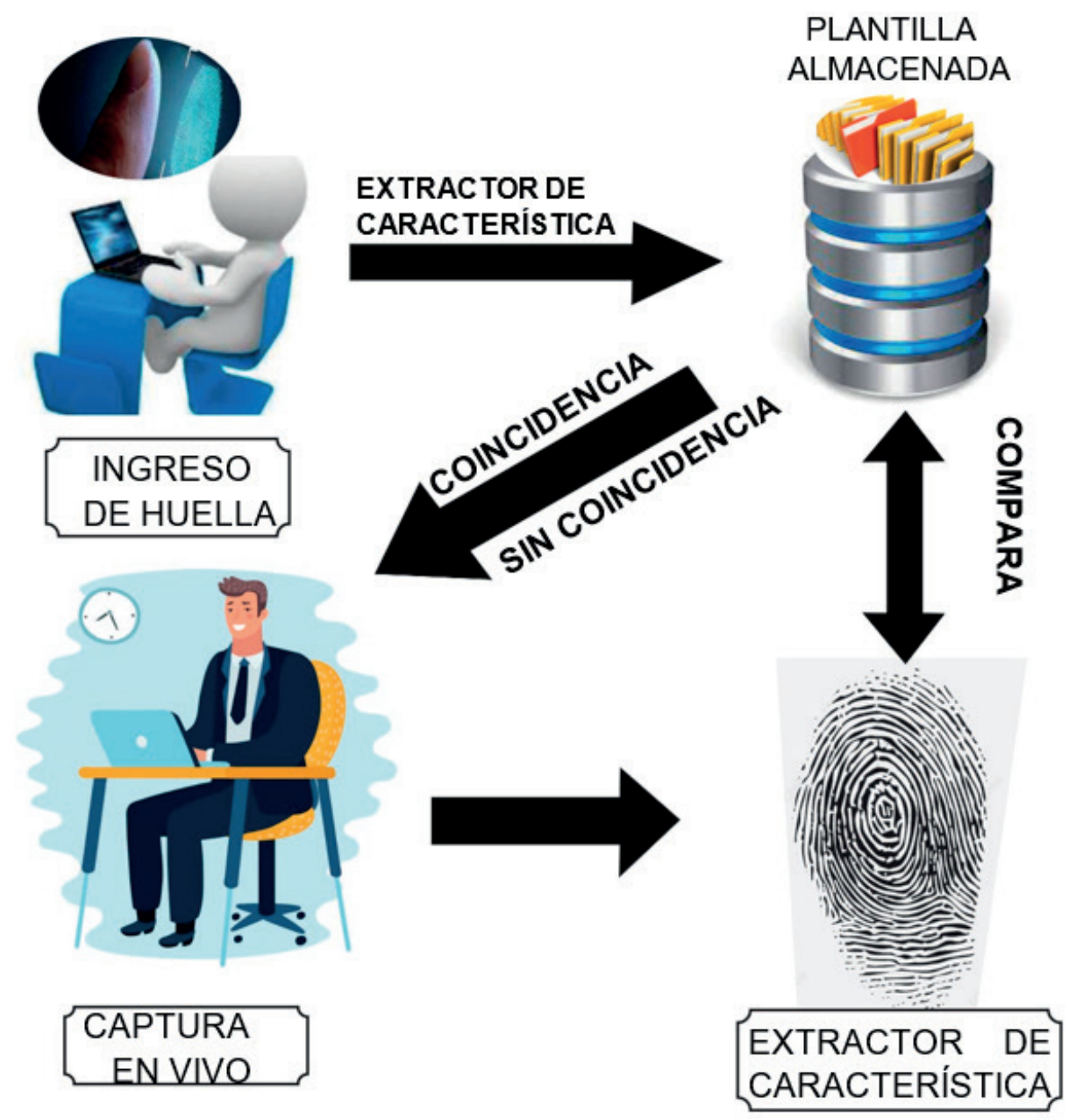

Figura 3. La arquitectura de los procesos de un sistema biométrico.

Fuente: Elaboración propia.

principio en común: El usuario no implementa la función de evaluación de manera explícita, sino simplemente provee al ordenador una forma de crear autónomamente esta función para después optimizarla a partir de la experiencia basada en datos de aprendizaje. En otras palabras, el usuario no introduce los criterios empleados por la computadora, es esta quien determina los criterios utilizando un algoritmo en particular.

En este proyecto, se emplea específicamente un algoritmo denominado K-Means (o K Medias), que es un algoritmo de segmentación/clusterización de datos. Este método fue propuesto formalmente por primera vez el año 1957 por el matemático Stuart P. Lloyd, aunque su publicación oficial data del año 1982, en el artículo titulado Least Squares Quantization in PCM. Este algoritmo ha sido optimizado varias veces en las décadas subsiguientes, hasta llegar a implementaciones recientes. El K-Means consiste en la segmentación de un conjunto de puntos en un espacio euclidiano de la siguiente manera: Primero, el algoritmo asigna k centroides de manera aleatoria (donde $\mathrm{k}$ es un valor arbitrario escogido por el usuario). Los clusters son entonces segmentados de acuerdo a la mínima distancia de cada punto con cada uno de estos centroides como se muestra en la figura 4.

Una vez que los k clusters están formados, se recalculan los centroides empleando la media del conjunto de puntos pertenecientes a cada cluster, como se observa en la Figura 5. El algoritmo es iterativo, por lo que el proceso se repite hasta que los centroides convergen. En este caso, convergencia significa que los clusters formados permanecen constantes incluso en las iteraciones subsiguientes. Cabe resaltar que la convergencia de este algoritmo en una cantidad finita de iteraciones ya 


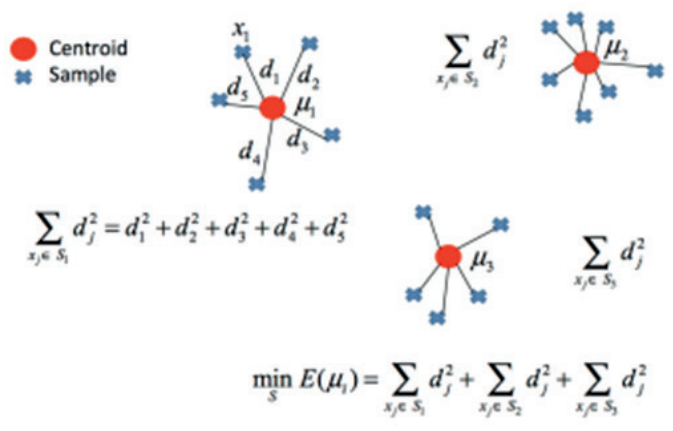

Figura 4. Algoritmo K-Means.

Fuente: Zúñiga (s.f.).

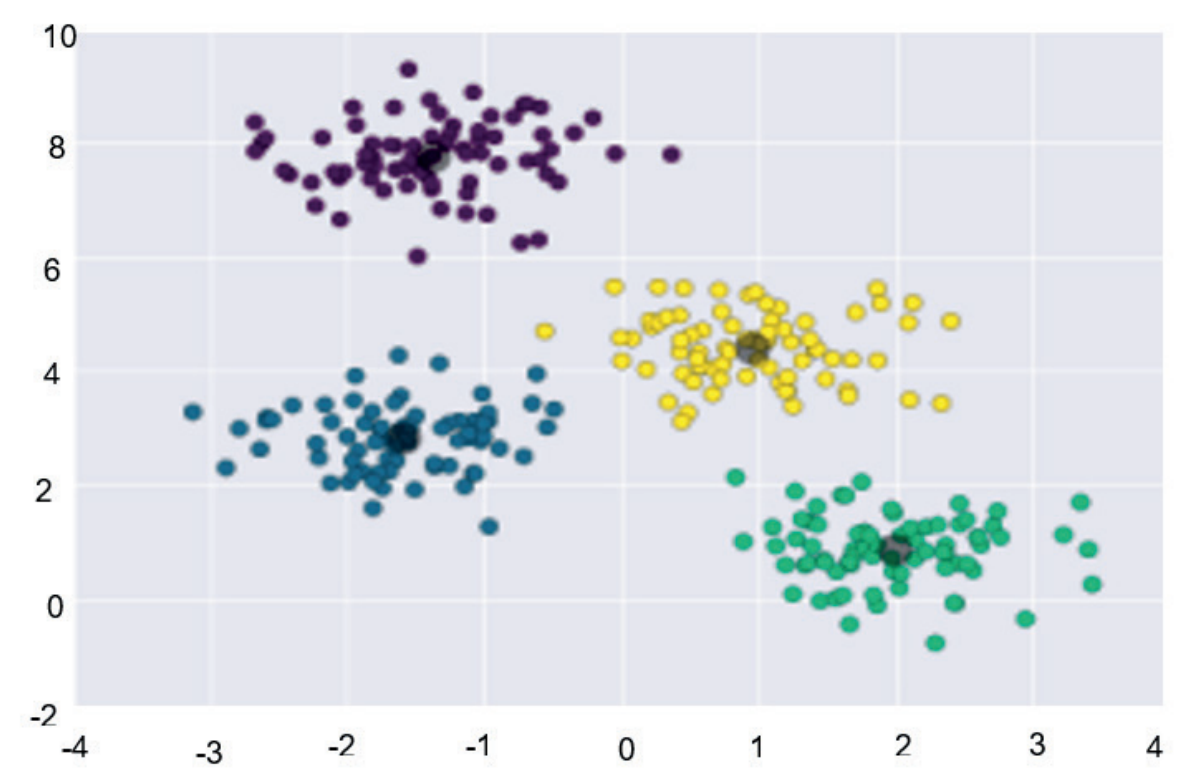

Figura 5.Agrupación de datos bajo criterio del algoritmo K-Means.

Fuente: VanderPlas, J. (2017).

ha sido demostrada, por lo que siempre es posible llegar a un final.

\section{METODOLOGÍA}

Se realizó la revisión documental del tema de investigación, se analizó la información escrita sobre la búsqueda de huella dactilar en una base de datos grande y se encontró un buen número de artículos relacionados al tema en las bases de datos indexadas de los últimos años. Se revisó cada uno de los artículos encontrados en la búsqueda de información, lo que resultó ser relevante para ampliar y definir la visión del tema; de esta forma, se genera el aporte adecuado a la solución de este tipo de problemas.

Se finalizó con el planteamiento de segmentación de la base de datos a gran escala en segmentos que agrupen las huellas dactilares por sus características, para luego seleccionar un solo segmento donde se realizaría la búsqueda de la huella a identificar; este modelo contempla tener un tiempo de respuesta eficiente al realizar la búsqueda de una determinada huella en una base de datos muy grande.

\section{ANTECEDENTES}

\section{Clasificación huellas dactilares usando curvas de flujo de campo de orientación}

Los autores Dass y Jain (2004) revisan las diferentes series de enfoque que se han desarrollado sobre la clasificación de las huellas dactilares; además, verifican que los métodos híbridos desarrollados no han sido probados en grandes bases de datos. Asimismo los autores indican que las clases que se utilizan para la clasificación son importantes. Otros investigadores han empleado cuatro clases 
que no resultaron ser efectivas en la clasificación; por lo tanto, en este caso los autores plantean cinco clases para obtener mejores resultados.

De acuerdo a lo expresado por Dass y Jain (2004), el procedimiento que utilizaron casi logró determinar la clasificación de las huellas digitales con un porcentaje de $94.4 \%$ de exactitud, por lo que proponen, en un trabajo a futuro, incluir en su estudio la detección de las zonas donde se originan los bucles más pequeños, además de seguir tomando como base la clasificación propuesta por Henry (1900), que consiste en: arco, arco derecho, arco, arco de carpa y circular o espiral.

El procedimiento utilizado se basa en la base de datos NIST4 (Instituto Nacional de Estándares y Tecnología), y el enfoque usado para el desarrollo es una combinación del enfoque estructural, sintáctico y netamente basado en las matemáticas (Watson y Wilson, 1992).

\section{Un método eficaz de clasificación y búsqueda de huellas dactilares}

La clave para la tarea de clasificación de imágenes de huellas dactilares son las características. La eficacia de la extracción de las caracterizadas depende de la calidad de las imágenes, la representación de los datos de la imagen, de los modelos de procesamiento de imágenes y la evaluación de la extracción de la característica.

La evaluación en tiempo real de la calidad de la imagen ofrece mejorar mucho la precisión del sistema de identificación. La buena calidad de las imágenes requiere menor pretratamiento y mejora. Por el contrario, las imágenes de baja calidad requieren mayor pretratamiento y, por supuesto, mejora. Para que la búsqueda de huellas dactilares sea eficiente, se requiere que las imágenes de la huella dactilar sean de buena calidad.

La mayoría de los métodos clasifican las huellas dactilares en cuatro o cinco clases con un nivel de precisión de $80 \%$ a $95 \%$. El método propuesto por los autores las clasifica en seis clases con las cuales se obtiene un nivel de precisión del $97 \%$, lo que muestra una mejora con respecto a los anteriores (Bhuvan y Bhattacharyya, 2009).

Un sistema de emparejamiento en tiempo real para grandes bases de datos de huellas dactilares

La técnica que mencionan Ratha, Karu, Chen, y Jain (1996) es más simple: consiste en colocar las imágenes en la base de datos como un texto plano, el cual es una secuencia de caracteres con la información de cada píxel. El principal inconveniente de este método es que la escena de descripción puede ser diferente en momentos diferentes para el mismo, dependiendo del contexto de la consulta. Los autores se sienten motivados cuando observan el gran espacio que ocupan estos datos al ser almacenados y plantean reducirlo usando técnicas de extracción de características.

Una base de datos de huellas digitales se caracteriza por un gran número de registros (del orden de millones). El tamaño de la base de datos del FBI ha crecido de más de 0.8 millones de tarjetas de huellas dactilares (diez huellas dactilares por tarjeta), en 1924, a más de 114 millones de tarjetas de huellas dactilares en 1994. El requisito de almacenamiento para una colección tan grande de imágenes se ejecuta en 1.140 terabytes sin compresión. Además, se espera que el tipo de consulta de este sistema difiera radicalmente de los otros dominios de aplicación de bases de datos de imágenes.

La imagen del mismo objeto puede variar dependiendo de su orientación, la luz ambiente y el sensor. El sentido de la información es de una dimensionalidad mucho mayor que la información textual. En una biblioteca digital hay principalmente tres componentes: captura de datos, gestión del almacenamiento y técnicas de búsqueda y consulta.

Según la propuesta de Ratha et al. (1996), se separa la información de las imágenes en sus características para guardarlas en la base de datos. De esta forma, solo hace falta tomar una foto de la huella de una persona y verificarla con las características propias de la persona.

A menudo, la mala calidad de las imágenes reduce la precisión del sistema. Por lo tanto, de acuerdo con Douglas (1993), se está considerando una evaluación de calidad de imagen en la etapa de entrada.

\section{Modelo de búsqueda secuencial}

Como se observa en la Figura 6, actualmente la búsqueda de huellas dactilares en una gran base de datos demanda demasiado tiempo de respuesta cuando se realiza una búsqueda secuencial, aun cuando la base de datos está ordenada, por lo que esta búsqueda se puede relacionar con el valor tiempo-costo.

\section{Búsqueda secuencial de una huella dactilar}

Dado el ingreso de una imagen de una huella digital (ver Figura 6), en formato bmp, esta se representa en una matriz cuyos elementos son ceros y unos. Luego, se realiza la conexión a la base de datos 
para buscar dicha matriz que tiene el tipo BLOB (Binary Large Object).

El siguiente código explica como el SQLite realiza una búsqueda secuencial registro por registro, y retorna una lista. Si el elemento ha sido encontrado, esta lista tiene un tamaño mayor a cero. De lo contrario, el tamaño es cero. Lo cual nos permite determinar cuándo una búsqueda ha sido exitosa (ver Figura 7).

\section{Modelo propuesto}

El modelo que se plantea segmenta la base de datos de gran magnitud en segmentos según las características de cada una de las huellas, de tal manera que la búsqueda no se realice en toda la base de datos sino en un determinado segmento; luego, en este segmento seleccionado, se realiza la búsqueda, y así se obtiene un resultado inmediato de la identificación de la huella buscada, como se muestra en la Figura 8.

En primer lugar, se ingresa la huella dactilar de la persona que debe ser identificada. A través del ordenador, se ejecuta la aplicación de clasificación de la huella ingresada, la cual retornará el número de segmento correspondiente encontrado en la base de datos ya entrenada en la fase de entrenamiento del modelo para la respectiva búsqueda. Esta base de datos contiene todas las huellas dactilares almacenadas, en ella se encuentra la huella a identificar. Buscar en la base de datos no segmentada demanda un tiempo de respuesta muy

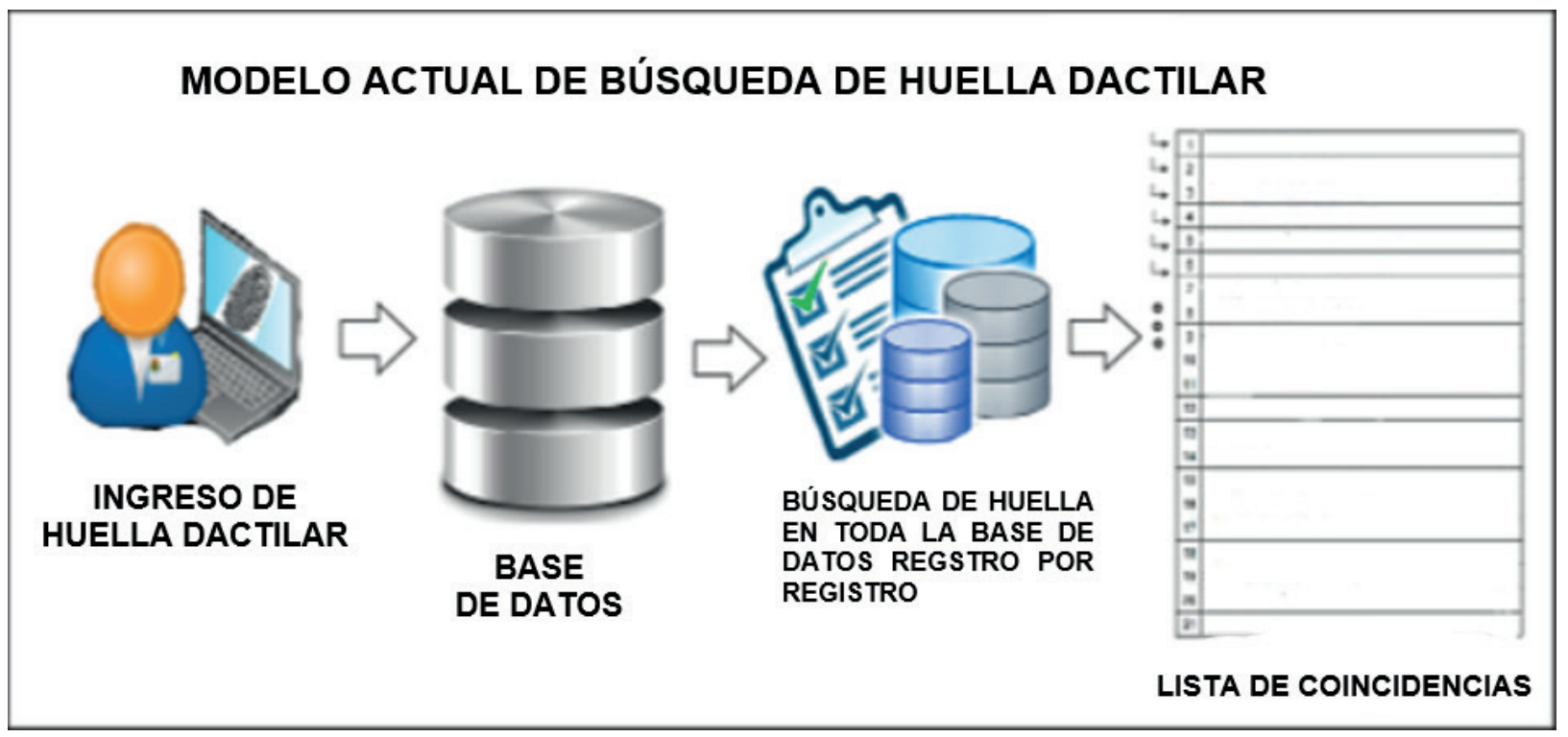

Figura 6. Modelo actual de búsqueda de huellas dactilares Fuente: Elaboración propia

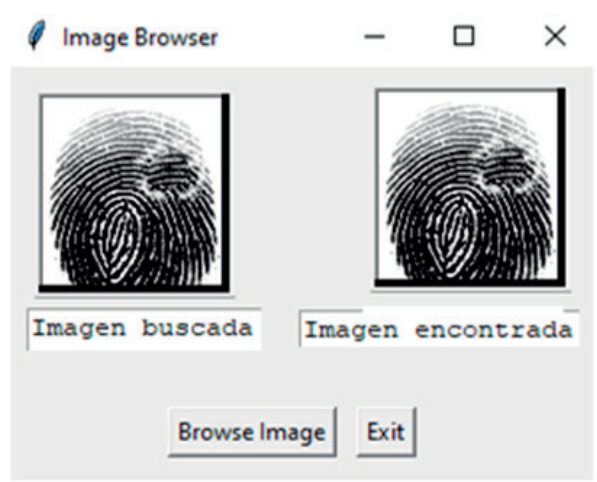

Figura 7. Huella ingresada y huella encontrada.

Fuente: Elaboración propia 


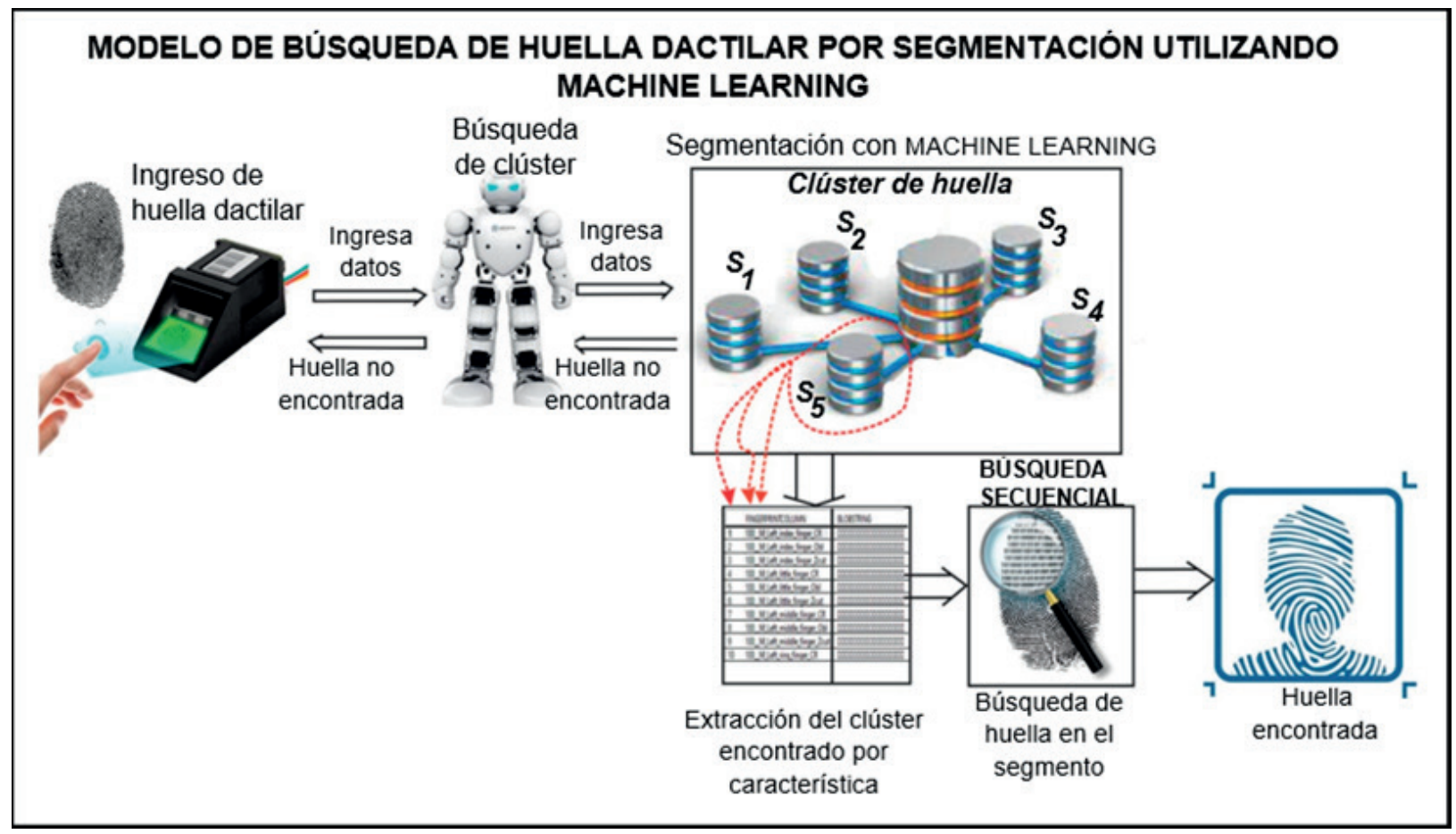

Figura 8. Modelo de búsqueda de huellas dactilares en grandes bases de datos.

Fuente: Elaboración propia

largo que, en algunos casos, es fundamental para tomar una decisión.

La base de datos que almacena las huellas dactilares es grande, por lo que, al realizar una búsqueda secuencial, esta tarda un tiempo considerable en dar la respuesta, a pesar de que la base de datos esté indexada. Dichas huellas dactilares cuentan con ciertas características que permiten clasificarlas en segmentos, lo que permite realizar la búsqueda solamente en el segmento seleccionado, donde se encuentra la huella a buscar. Para la segmentación se utiliza machine learning, específicamente el algoritmo K-Means, que permite agrupar las huellas según las características que el algoritmo identifica como más próximas. Al usar este método se segmenta la base de datos en cinco clusters (segmentos).

Al ingresar la huella que se va a buscar, se clasifica según el número de segmento que la contiene. Luego de ser ubicada en el segmento seleccionado, se realiza una búsqueda en ese segmento utilizando un algoritmo discreto. Como se observa, la búsqueda ya no se realiza en toda la base de datos, sino solamente en el segmento seleccionado. Así, se observa que al realizar la búsqueda en un solo segmento la huella buscada se identifica en un tiempo óptimo.

\section{Funciones y módulos}

\section{- Búsqueda secuencial no segmentada}

En el presente script se realiza la búsqueda secuencial de una imagen en una base de datos no segmentada, donde el objetivo principal es obtener el tiempo que demora el algoritmo en encontrar el par en búsqueda y se muestra en la interfaz.

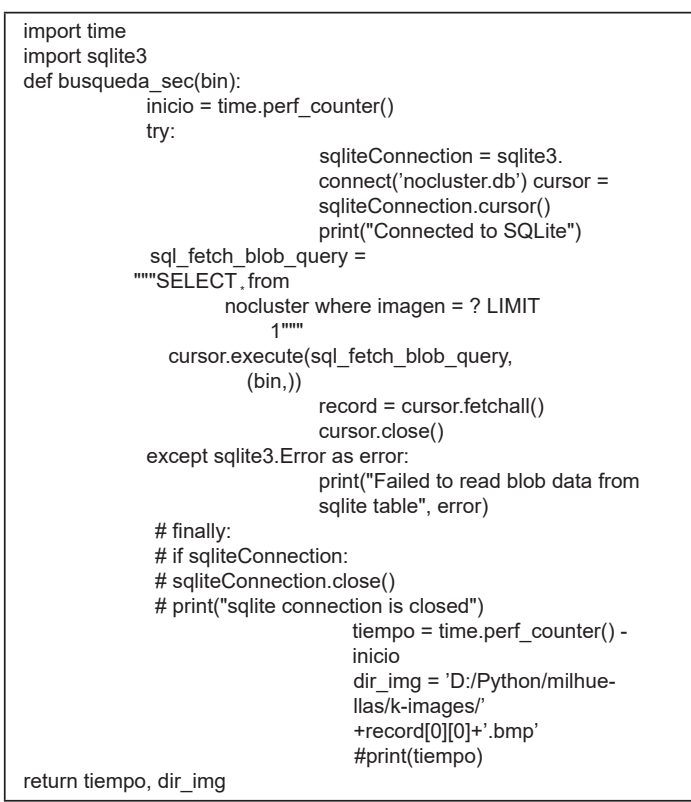




\section{- Predicción y búsqueda}

Se carga un modelo entrenado previamente que se aplicará para predecir en que cluster se encuentra la imagen a buscar, luego se aplica el algoritmo de búsqueda secuencial en dicho cluster, se captura el tiempo de todo el proceso y se muestra en la interfaz.

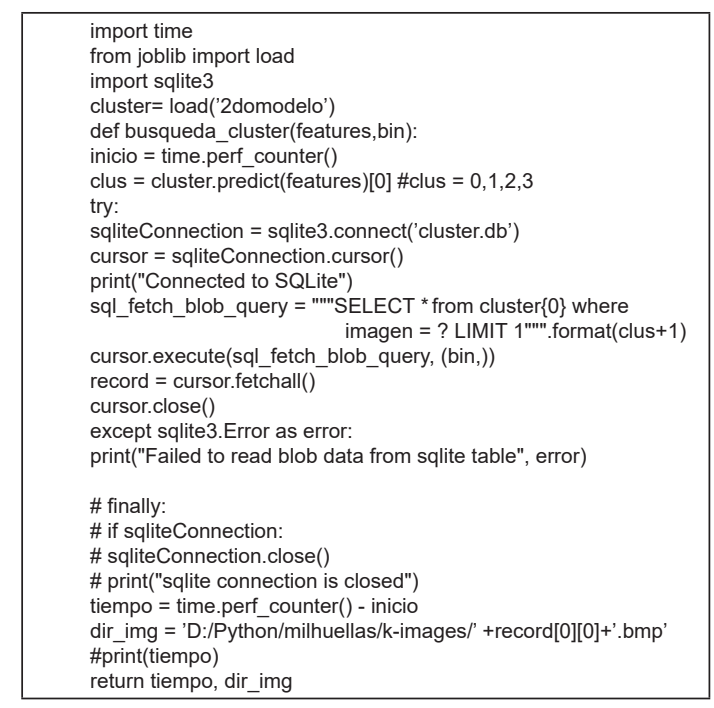

\section{- Otras funciones necesarias}

La función image_feature necesita de InceptionV3, que es una red neuronal convolucional para ayudar en el análisis de imágenes y la detección de objetos y que comenzó como un módulo para Googlenet.

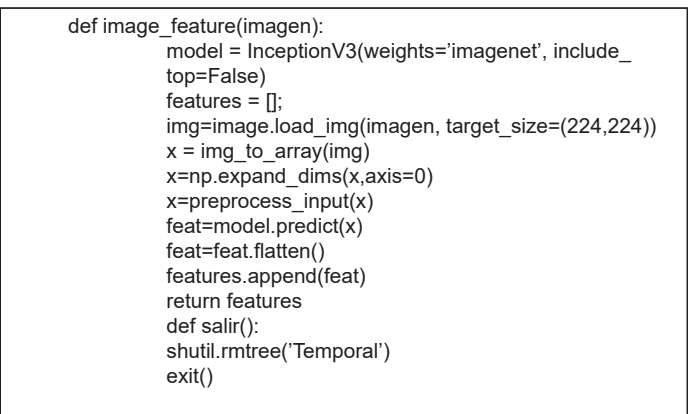

\section{Pruebas de tiempo}

Finalmente, tras la implementación del algoritmo en el programa, se debe determinar el tiempo de procesamiento de cada búsqueda para la comparación correspondiente. Se toman 50 imágenes escogidas aleatoriamente sin repetición con la finalidad de analizar la evolución del tiempo de búsqueda con relación a la posición de la imagen en la base de datos no clusterizada. Tras la ejecución de los algoritmos previamente expuestos, se determinaron los resultados que se muestran en la Tabla 2.
La primera columna describe la posición de la imagen en la base de datos, mientras que las siguientes dos columnas muestran el tiempo de búsqueda en segundos de la imagen usando los algoritmos segmentado y secuencial, respectivamente.

En conclusión, el experimento desarrollado permite confirmar que el algoritmo de búsqueda segmentada presenta ventajas sobre el algoritmo secuencial clásico. Esto principalmente debido a los dos siguientes motivos:

- La búsqueda secuencial en un cluster es considerablemente menor en promedio al tiempo de búsqueda en la base de datos completa.

- El tiempo de evaluación de una imagen en el modelo de clasificación es lo suficientemente breve como para no exceder al tiempo de búsqueda del algoritmo secuencial.

En la figura 9 se observa que la intersección de las rectas de tiempo secuencial y tiempo segmentado se da en el punto 112.5; luego, de acuerdo con los diagramas de regresión realizados, se puede deducir que para una base de datos de 537 imágenes, el punto donde la búsqueda secuencial empieza a tomar más tiempo es a partir de la imagen en la posición 113 en la base de datos no segmentada.

\section{DISCUSIÓN}

El enfoque de Dass y Jain (2004) tiene cuatro etapas principales: primero, la extracción del campo de orientación para la imagen de la huella dada; segundo, la generación de orientación de campo flujo curvas (OFFCs); tercero, el etiquetado de cada OFFC en las cuatro clases: bucles izquierdo y derecho, espiral y arco; y, por último, una clasificación general de la imagen de huella digital en una de las cuatro clases basada netamente en las matemáticas (el valor de la orientación de la imagen de la huella digital es un vector) y utilizando métodos de la geometría diferencial. De acuerdo con lo expresado por Dass y Jain (2004), con el procedimiento que utilizaronen lograron determinar la clasificación de las huellas digitales con un porcentaje de $94.4 \%$ de exactitud.

El propósito de este artículo es proponer un método de búsqueda totalmente eficiente aplicando machine learning, el cual obtiene una segmentación de las huellas dactilares de una base de datos grande y la agrupa según las características de cada huella en segmentos. Luego, se aplica un algoritmo de búsqueda secuencial en uno de los segmentos seleccionados, es decir, el que contiene la huella 
Tabla 2. Tiempo de búsqueda del algoritmo propuesto.

\begin{tabular}{|c|c|c|c|}
\hline Nro. & Nro. Huella & $\begin{array}{c}\text { Tiempo } \\
\text { Segmentado (s) }\end{array}$ & $\begin{array}{c}\text { Tiempo } \\
\text { Secuencial (s) }\end{array}$ \\
\hline 1 & 531 & 0.004379 & 0.008464 \\
\hline 2 & 528 & 0.004228 & 0.008589 \\
\hline 3 & 517 & 0.004777 & 0.008337 \\
\hline 4 & 513 & 0.004227 & 0.008667 \\
\hline 5 & 506 & 0.003872 & 0.008317 \\
\hline 6 & 490 & 0.003828 & 0.008067 \\
\hline 7 & 486 & 0.005438 & 0.008955 \\
\hline 8 & 483 & 0.005157 & 0.010635 \\
\hline 9 & 480 & 0.004468 & 0.008513 \\
\hline 10 & 472 & 0.006281 & 0.015658 \\
\hline 11 & 444 & 0.002972 & 0.007607 \\
\hline 12 & 442 & 0.003441 & 0.007469 \\
\hline 13 & 437 & 0.003763 & 0.007042 \\
\hline 14 & 428 & 0.004522 & 0.016173 \\
\hline 15 & 408 & 0.004283 & 0.006484 \\
\hline 16 & 397 & 0.004105 & 0.008492 \\
\hline 17 & 392 & 0.004123 & 0.007803 \\
\hline 18 & 390 & 0.004025 & 0.006753 \\
\hline 19 & 377 & 0.003137 & 0.006483 \\
\hline 20 & 356 & 0.010098 & 0.014196 \\
\hline 21 & 337 & 0.003842 & 0.008346 \\
\hline 22 & 316 & 0.008645 & 0.013955 \\
\hline 23 & 312 & 0.003817 & 0.006923 \\
\hline 24 & 309 & 0.003928 & 0.005397 \\
\hline 25 & 272 & 0.003292 & 0.006387 \\
\hline
\end{tabular}

\begin{tabular}{|c|c|c|c|}
\hline Nro. & Nro. Huella & $\begin{array}{c}\text { Tiempo } \\
\text { Segmentado (s) }\end{array}$ & $\begin{array}{c}\text { Tiempo } \\
\text { Secuencial (s) }\end{array}$ \\
\hline 26 & 268 & 0.002802 & 0.004809 \\
\hline 27 & 264 & 0.009219 & 0.008393 \\
\hline 28 & 261 & 0.003089 & 0.005612 \\
\hline 29 & 259 & 0.003477 & 0.006325 \\
\hline 30 & 247 & 0.007648 & 0.008603 \\
\hline 31 & 237 & 0.007601 & 0.009455 \\
\hline 32 & 236 & 0.009113 & 0.005527 \\
\hline 33 & 233 & 0.003252 & 0.006325 \\
\hline 34 & 222 & 0.003704 & 0.005572 \\
\hline 35 & 211 & 0.008135 & 0.010234 \\
\hline 36 & 179 & 0.003113 & 0.003579 \\
\hline 37 & 173 & 0.002846 & 0.002438 \\
\hline 38 & 163 & 0.003166 & 0.002587 \\
\hline 39 & 156 & 0.002703 & 0.002495 \\
\hline 40 & 153 & 0.002625 & 0.002485 \\
\hline 41 & 144 & 0.002265 & 0.002865 \\
\hline 42 & 138 & 0.002307 & 0.002889 \\
\hline 43 & 121 & 0.002772 & 0.001929 \\
\hline 44 & 91 & 0.005962 & 0.003999 \\
\hline 45 & 80 & 0.002847 & 0.001563 \\
\hline 46 & 78 & 0.002946 & 0.001216 \\
\hline 47 & 66 & 0.002495 & 0.001253 \\
\hline 48 & 64 & 0.002835 & 0.001167 \\
\hline 49 & 42 & 0.002091 & 0.001048 \\
\hline 50 & 9 & 0.003076 & 0.000588 \\
\hline
\end{tabular}

Fuente: Elaboración propia.

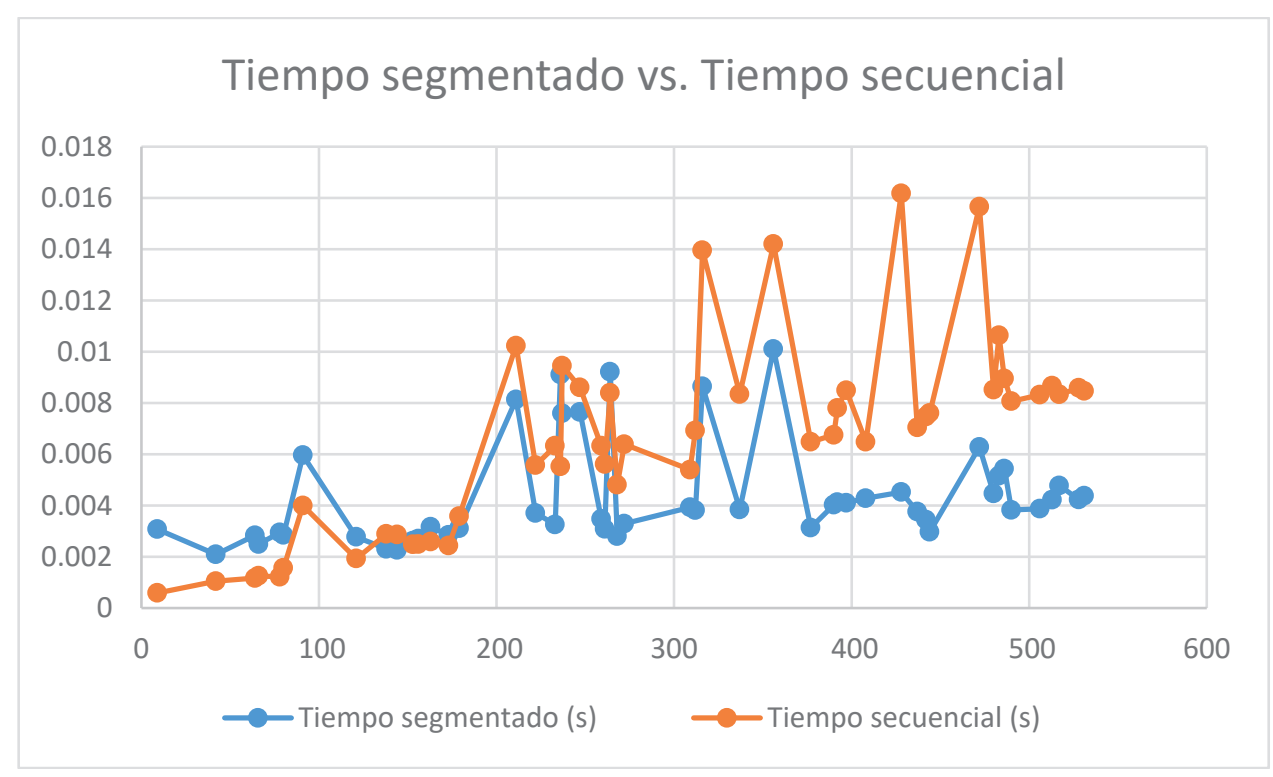

Figura 9. Gráfica de tiempos.

Fuente: Elaboración propia. 
a identificar. La propuesta de este modelo es minimizar los tiempos de búsqueda y se logra una confianza al $95 \%$. Se demuestra también en esta investigación que la búsqueda segmentada es más eficiente que realizar una búsqueda secuencial en una base de datos grande, lo que también es más eficiente que el método utilizado por Dass y Jain (2004).

\section{CONCLUSIONES}

El presente artículo tiene como objetivo principal minimizar tiempos en el motor de búsqueda al realizar la identificación de una persona en una gran base de datos. Tras la evaluación de métodos y algoritmos existentes, el aporte concluye que al emplear machine learning se consigue segmentar una gran base de datos agrupando las huellas dactilares por sus características más próximas y aplicando luego una técnica de búsqueda secuencial en solo un segmento seleccionado para encontrar la huella dactilar de la persona en términos eficientes.

Este modelo no busca la huella en toda la base de datos, pues ello demanda un tiempo de respuesta muy alto. Lo que se plantea con esta propuesta es realizar la búsqueda solo en uno de los segmentos clasificados por características, donde se encontraría la huella buscada, con lo que se reduce el tiempo de búsqueda.

\section{RECOMENDACIONES}

En el estudio de la investigación en relación al tema "Búsqueda de huellas dactilares en gran base de datos", se sugiere una metodología documental y exhaustiva conservando el modelo propuesto en el tema del artículo de investigación. Al realizar la segmentación se recomienda utilizar algoritmos genéricos, que son métodos adaptativos que pueden usarse para resolver problemas de búsqueda y optimización con la finalidad u objetivo único de optimizar en tiempo los resultados finales.

También se recomienda realizar pruebas con una muestra más grande para probar la eficiencia del modelo propuesto.

\section{REFERENCIAS BIBLIOGRÁFICAS}

[1] Bathia, S., y Deogun, J. (1998). Conceptual Clustering in Information Retrieval. IEEE Transactions on Systems, Man and Cybernetics, Part B: Cybernetics, 28(3), 427-436.

[2] Bhuvan, M., y Bhattacharyya, D. (2009). An Effective Fingerprint Classification and Search
Method. IJCSNS International Journal of Computer Science and Network Security, 3948.

[3] Dass, S., y Jain, A. (2004). Fingerprint Classification Using Orientation Field Flow Curves In. ICVGIP. 650 - 655.

[4] Douglas H., D. (Nov. de 1993). Enhancement and Feature Purification of Fingerprint Images. Pattern and Recognition, 26(11), 1661-1671.

[5] Fayyad, U., Piatetsky-Shapiro, G., y Smyth, P. (1996). From data Mining to Knowledge Discovery in Databases. American Association for Artificial Intelligence, 37-54.

[6] Fernández, F. A. (2008). Biometric sample quality and its application to multimodad authentication systems. (Tesis doctoral). Universidad Politécnica de Madrid, Madrid.

[7] Forgy, E. (1965). Cluster analysis of multivariate data: E_ciency vs. Interpretability of classifications. Biometrics, 21, 768.

[8] Henry, E. R. (1900). Classification and Uses of Fingerprints.

[9] Kearns, M., Mansour, Y., y Ng, A. (1997). An information-theoretic analysis of hard and soft assignment methods for clustering. (K. M. Publishers, Ed.) Proceedings of the Thirteenth Conference on Uncertanly in Artificial Intelligence, 282-293.

[10] MacQueen, J. (1967). Some methods for classification and analysis of multivariate observations. Proceedings of the fifth Berkeley symposium on mathematical statistics and probability, 1(14), 281-297.

[11] Makhoul, J., Roucos, S., y Gish, H. (1985). Vector Quantization in Speech Coding. Proccedings of the IEEE, 73(11), 1551 - 1588.

[12] Maltoni, D., Maio, D., Jain, A., y Prabhakar, S. (2003). Multimodal Biometric Systems. En Handbook of fingerprint recognition (págs. 233255). New York, NY: Springer.

[13] Persto S.A. de C.V. (15 de junio de 2020). Verificación de identidad biométrica. Recuperado de http://www.persto.com/

[14] Pham, D., y Prince, J. (1999). An Adaptive Fuzzy C-Means Algorithm for Image Segmentation in the Presence of Intensity Inhomogeneities. Pattern Recognition Letters, 20(1), 57-68.

[15] Ratha, N. K., Karu, K., Chen, S., y Jain, A. (1996). A real-time matching system for large fingerprint databases. IEEE transactions on 
pattern analysis and machine inteliigence, 18(8), 793-813.

[16] Scheunders, P. (1997). A comparison of clustering algorithms applied to color image quantization. Pattern Recognition Letters, 18(11-13), 1379 - 1384.

[17] Solberg, A., Taxt, T., y Jain, A. (1996). A Markov Random Field Model for Classification of Multisource Satellite Imaginery. IEEE Transactions on Geoscience and Remote Sensing, 34(1), 100 - 113.

[18] VanderPlas, J. (2017). Python Data Science Handbook. Essential Tools for Working wit Data. Sebastopol, CA 95472, EE. UU.: O'Reilly Media, Inc.

[19] Villamizar, J. A. (1994). Procesamiento y clasificación de huellas dactilares. Lecturas Matemáticas, 15(2), 149 -165.
[20] Watson C.I., y Wilson, C. (March de 1992). Nits 4, Special Database. National Institute of Standars and Technology.

[21] Wayman, J., Jain, A. K., Maltoni, D., y Maio, D. (Eds.) (2005). Biometric Systems: Technology, Design and Performance Evaluation. Springer Science \& Business Media.

[22] Zúñiga, J. (s.f.). El algoritmo k-means aplicado a clasificación y procesamiento de imágenes. Recuperado el 15 de julio de 2021 de https:// www.unioviedo.es/compnum/laboratorios_py/ new/kmeans.html 


\section{Efficient Search Method to Solve the Fingerprint Identification Problem by Applying Machine Learning}

María Elena Ruiz Rivera ${ }^{1}$ EDGar RuIZ LizAMA ${ }^{2}$

\begin{abstract}
In biometrics technology, the fingerprint identification problem has been widely studied over the last decades due to its applicability in person identification cases. In casualty cases, recognition of the victim is required, which should be done unequivocally using fingerprint identification. The aim of this research is to innovate the fingerprint identification process, developing an efficient search method in a large database that allows finding a fingerprint in less time by classifying fingerprints into segments, according to their closest characteristics, using machine learning. Then, in a given segment, a discrete linear search algorithm is applied, with which the required fingerprint is located.
\end{abstract}

Keywords: Fingerprint; biometrics; machine learning; fingerprint search.

\section{INTRODUCTION}

As a result of the increase in technology regarding communication and data transfer through networks, the use of fingerprint systems has become common in forensics and law enforcement, both in government and private institutions. One example of this is at banks, where the fingerprint is verified for cash withdrawals, which provides security to the customer against identity theft or impersonation. Another example is when a criminal enters the operating room with the purpose of undergoing several aesthetic surgeries to significantly change his/her physical appearance; the identity of this person is revealed thanks to his/her fingerprint, which is unique and unrepeatable. Similarly, in the case of a person disfigured by an accident, his or her unequivocal recognition is possible thanks to his or her fingerprints.

Investigation is based on the search for information in large databases, so the response time is reflected in very high costs; thus, the search for images further complicates the collection of information. Storing a digital image requires a large memory space, so the cost increases for a large number of images. The search for this type of information can be performed using different types of algorithms; however, the response time and cost involved in searching these large databases, where response time is critical, must be taken into account.

The efficient fingerprint search leads to the general research objective, which is to propose an efficient fingerprint search method at a lower cost and time, in which machine learning is applied for segment classification and a discrete algorithm for linear search in a given segment.

1 Degree in Computer Science from Universidad Nacional Mayor de San Marcos (Lima, Peru) Currently working as professor at the School of Systems Engineering and Computer Science at the Universidad Nacional Mayor de San Marcos. ORCID: https://orcid.org/0000-0003-3300-7068 Corresponding author: mruizr@unmsm.edu.pe

2 Industrial Engineer from Universidad Nacional Mayor de San Marcos and Master in Computer Science from Pontificia Universidad Católica del Perú (Lima, Peru). Currently working as professor at the School of Industrial Engineering at Universidad Nacional Mayor de San Marcos.

ORCID: https://orcid.org/0000-0001-9403-1358

E-mail: eruizl@unmsm.edu.pe 
Performing a linear search in a large database generates a delay in the search time. Fingerprints have features that allow their classification, such as arch, right loop, left loop, tentarch and whorl (Dass \& Jain, 2004). The fingerprint search work presented here focuses only on fingerprints of individuals in a macro database in order to reduce the search time.

Fingerprint classification consists of systematically partitioning the database into different segments using machine learning. These segments are formed by the approximation of the characteristics of each fingerprint. The classification of fingerprints into segments significantly reduces the time spent on fingerprint identification, especially in situations where accuracy and speed are critical.

The proposed method consists of first classifying fingerprints by their characteristics using machine learning, so that it is possible to create groups by similar or closer characteristics; then, in a second step, using a discrete algorithm that allows performing a linear search and finding the required fingerprint.

\section{THEORETICAL FRAMEWORK}

\section{Biometric Systems}

A biometric system is essentially a pattern recognizer that captures biometric data from a person, extracts a set of features from that data, and compares them to other patterns previously stored in the system (Wayman, Lain, Maltoni, \& Maio, 2005).

A biometric system is an automated system that performs biometric tasks. That is, its recognition decisions are based on the physical or behavioral characteristics of a person in an automated manner (Fernández, 2008).

To solve these problems, methods are being developed based on certain biometric features that guarantee the identity of individuals. These biometric traits are classified into two types (Fernández, 2008), the first is physiological biometrics, based on body parts, such as fingerprints, iris, retina, voice, hand and face; the second is behavioral biometrics, based on a person's actions, such as a person's signature.

\section{Characteristics of a Biometric Indicator}

According to Fernández (2008), a biometric indicator is some characteristic with which biometrics can be performed, thus we have:
- Universality: the biometric trait exists for all individuals.

- Uniqueness: the biometric trait univocally identifies each person.

- Permanence: the biometric trait remains unchanged over time in the short term.

- Immutability: the biometric trait remains unchanged over time in the long term or throughout life.

- Measurability: the biometric trait is suitable for quantitative characterization.

- Performance: the biometric trait allows the individual to be recognized quickly, robustly and accurately.

- Acceptability: the biometric trait must be accepted by the majority of the population.

- Invulnerability: the biometric trait allows the system to be robust against fraudulent access methods.

Table 1 shows the various biometric technologies according to the degrees of confidence (high, medium, low) of the properties described above (Maltoni, Maio, Jain, \& Prabhakar, 2003).

\section{Biometric Identification}

Biometric identification has been defined by Professor Jain Lakhmi as the process of automatically linking the identity of an individual through the use of some physical or behavioral characteristics inherent to the person (Fernández, 2008).

\section{Fingerprint}

A fingerprint is the representation of the surface morphology of the epidermis of a finger (Persto, 2020). It forms in the fetal stage of the human being and is constituted by papillary ridges; it is also immutable throughout life, unless it suffers severe injury or damage (Villamizar, 1994).

\section{Fingerprint Characteristics}

In 1892, Francis Galton published the first classification system and established the individuality and permanence of fingerprints; the "fine details" that Galton identified are used today (Persto, 2020).

Dass and Jain (2004) based their work on the fingerprint classification of Henry (1900), who proposed five main fingerprint classes based on the NIST4: (a) left loop, (b) right loop, (c) arch, (d) tentarch, and (e) whorl. This classification is shown in Figure 1. 
Table 1. Comparison of Biometric Technologies.

\begin{tabular}{lccccccc}
\hline Biometric Indicator & Universality & Uniqueness & Permanence & Measurability & Performance & Acceptability & Invulnerability \\
\hline DNA & High & High & High & Low & High & Low & Low \\
Ear & Medium & Medium & High & Medium & Medium & High & Medium \\
Face & High & Low & Medium & High & Low & High & High \\
Facial thermograph & High & High & Low & High & Medium & High & Low \\
Fingerprint & Medium & High & High & Medium & High & Medium & Medium \\
Gait & Medium & Low & Low & High & Low & High & Medium \\
Hand geometry & Medium & Medium & Medium & High & Medium & Medium & Medium \\
Hand veins & Medium & Medium & Medium & Medium & Medium & Medium & Low \\
Iris & High & High & High & Medium & High & Low & Low \\
Keystroke & Low & Low & Low & Medium & Low & Medium & Medium \\
Smell & High & High & High & Low & Low & Medium & Low \\
Retina & High & High & Medium & Low & High & Low & Low \\
Signature & Low & Low & Low & High & Low & High & High \\
Voice & Medium & Low & Low & Medium & Low & High & High \\
\hline
\end{tabular}

Source: Data based on the perception of the authors of the book Handbook of Fingerprint (Maltoni et al., 2003).

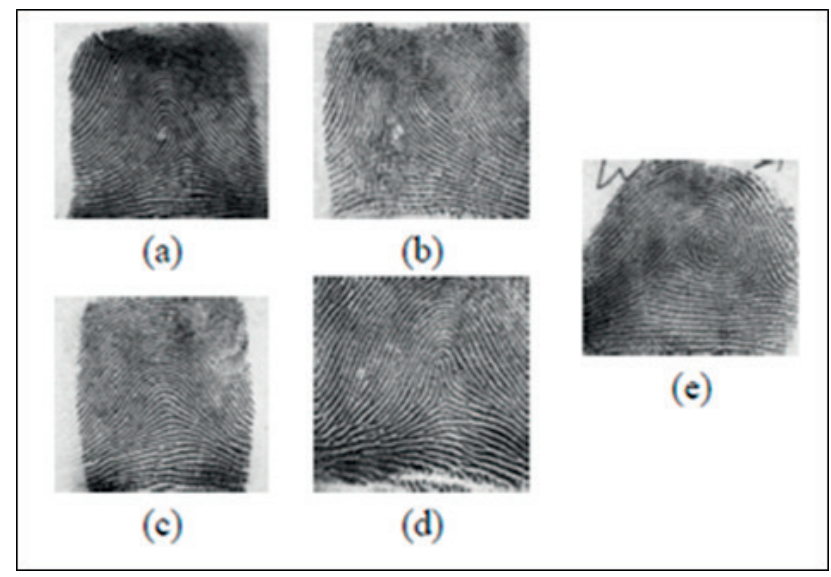

Figure 1. Fingerprint classification.

Source: National Institute of Standards and Technology (NIST4) special database (Dass \& Jain, 2004).

\section{Fingerprint Storage Module}

The fingerprint storage module is responsible for the analog or digital acquisition of some biometric indicator of a person, such as the acquisition of a fingerprint image using a scanner. Once the fingerprint is obtained, it is stored in the database (patterns or templates) from a biometric device. The process is depicted in Figure 2.

\section{Process Architecture of a Biometric System}

The process starts when the fingerprint is entered into a fingerprint recognition device with an optical fingerprint scanner. This device transforms the information into digits and captures the image of the entered fingerprint. Once digitized, the fingerprint is taken to the database (template) by means of mathematical algorithms according to its particular characteristic.

The fingerprint to be searched is then live captured, extracting its characteristics and running a search in the database where the fingerprints have been previously stored. If it finds matches with the image entered, the identity of the person to whom the image corresponds can be verified, which gives a positive result in the search. If no matches are found in the digitized image of the fingerprint, it is compared and gives a negative search result (see Figure 3 ). 


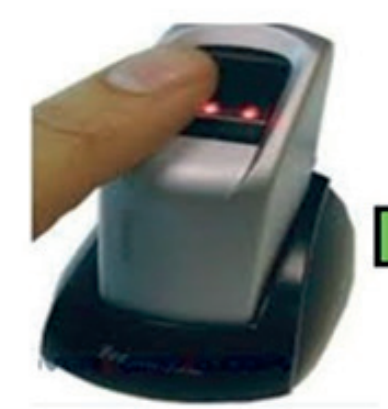

BIOMETRIC SENSOR

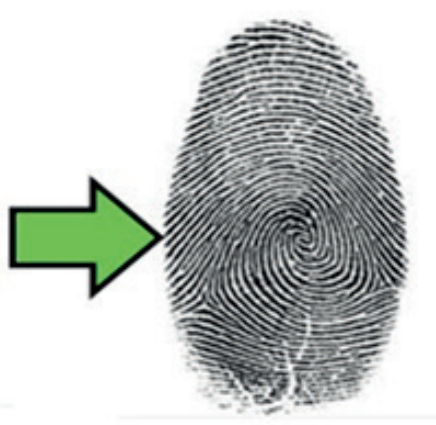

FINGERPRINT

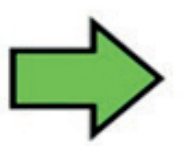

DATABASE

Figure 2. Fingerprint storage module of a biometric system. Source: Prepared by the authors.

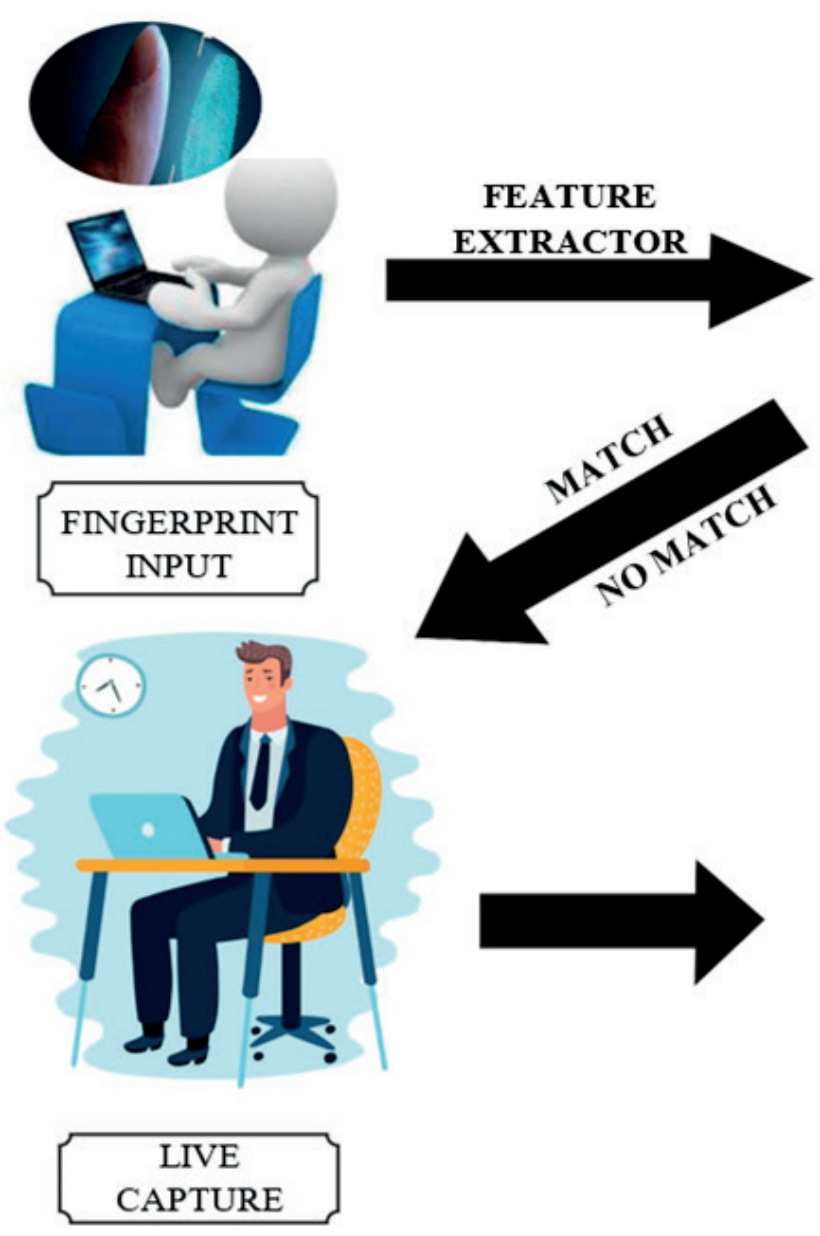

STORED TEMPLATE

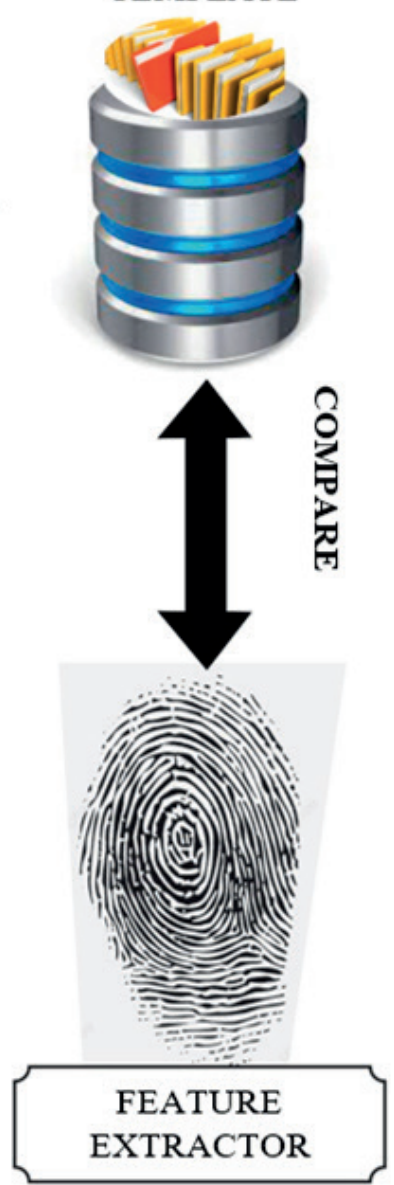

Figure 3. Process architecture of a biometric system. Source: Prepared by the authors.

\section{Clustering Method}

Clustering has various applications in computer science, such as image compression (Scheunders, 1997) and voice digitization (Makhoul, Roucos, \&
Gish, 1985); retrieval of related information (Bathia \& Deogun, 1998); data mining, where the search for groups with certain characteristics of interest is carried out (thus discovering new customer segments with the aim of improving the services provided) 
(Fayyad, Piatetsky-Shapiro, \& Padhraic, 1996); image segmentation by dividing the image into homogeneous regions (according to some characteristic of interest such as intensity, color or texture), which is especially important in medical applications (Pham \& Prince, 1999); and classification of satellite images into different zones (urban, open fields, rivers, forests) (Soldberg, Taxt, \& Jain, 1996).

Clustering methods differ from each other on how they compose the clusters. Those that do so according to the correspondence to a partition of the set of objects are known as hard clustering methods (Kearns, Mansour, \& Ng, 1997); of these, the best known is the k-means algorithm (Forgy, 1965; MacQueen, 1967).

\section{K-Means Algorithm}

K-means algorithm (Forgy, 1965) is a heuristic commonly used to solve the clustering problem (MacQueen, 1967). The basic idea of the algorithm is to have the initial $\mathrm{k}$ centers and to assemble clusters by associating the objects of $X$ to the nearest centers; then, the centers are recalculated. If the new centers do not differ from the previous centers, the algorithm terminates; otherwise, the association process is iterated with new centers until there is no variation in the centers or some new stopping criterion is established with a small number of reassignments of the objects for these methods.

\section{Machine Learning}

Machine learning is a set of computational algorithms that share a common principle: The user does not implement the evaluation function explicitly, but simply provides the computer with a way to autonomously create this function and then optimize it from experience based on learning data. In other words, the user does not enter the criteria used by the computer, the computer determines the criteria using a particular algorithm.

In this project, we specifically employ an algorithm called k-means, which is a data segmentation/ clustering algorithm. This method was formally proposed for the first time in 1957 by the mathematician Stuart P. Lloyd, although it was officially published in 1982 in an article entitled Least Squares Quantization in PCM. Several optimizations of this algorithm have been carried out over the decades, leading to recent implementations. K-means consists of segmenting a set of points in a Euclidean space as follows: First, the algorithm assigns $\mathrm{k}$ centroids randomly (where $k$ is an arbitrary value chosen by the user). The clusters are then segmented according to the minimum distance of each point from each of these centroids as shown in Figure 4.

Once the k clusters are formed, the centroids are recalculated using the average of the set of points belonging to each cluster, as shown in Figure 5. The algorithm is iterative, so the process is repeated until the centroids converge. In this case, convergence means that the clusters formed remain constant even in subsequent iterations. It should be noted that the convergence of this algorithm in a finite number of iterations has already been demonstrated, so it is always possible to reach an end.

\section{METHODOLOGY}

The literary review was carried out, the written information on the fingerprint search was analyzed in a large database and a good number of articles related to the topic were found in the indexed databases of recent years. Each of the articles found in the information search was reviewed, which turned out to be relevant to broaden and determine the scope of

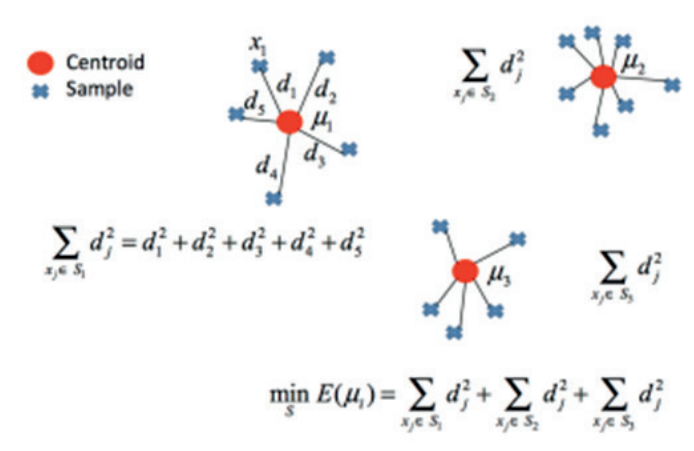

Figure 4. K-means algorithm.

Source: Zúñiga (n.d.). 


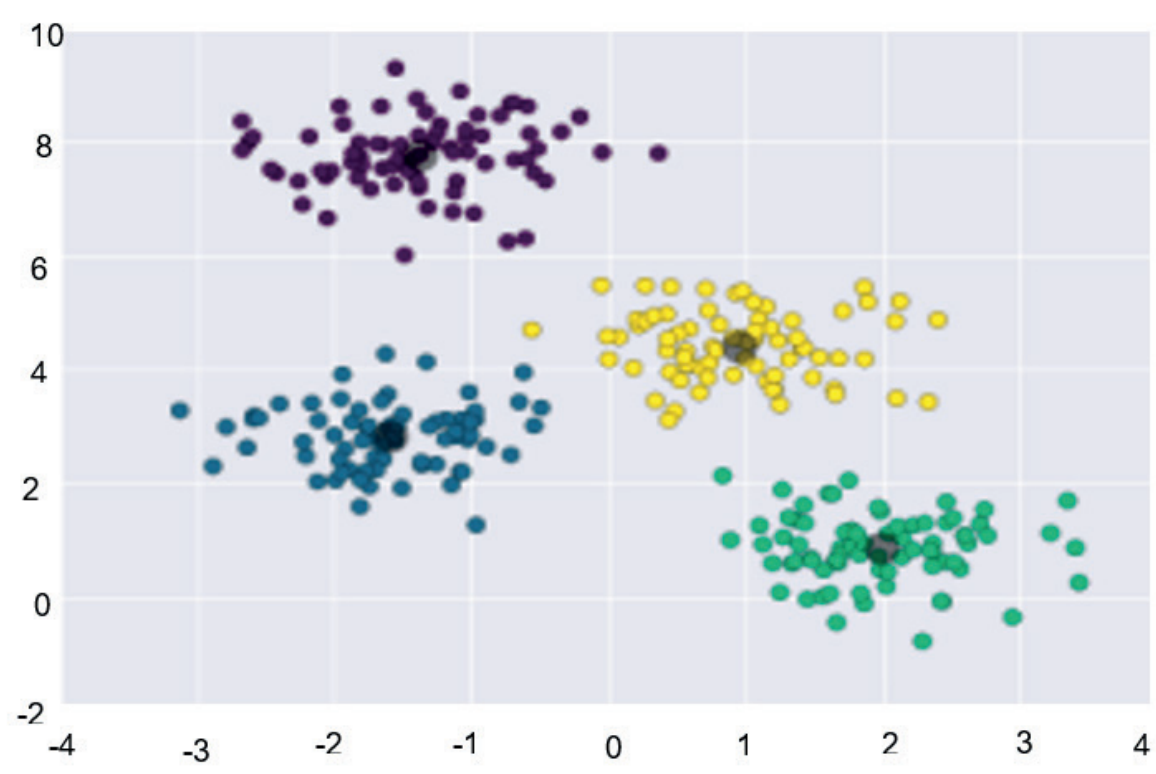

Figure 5. Data clustering under k-means algorithm criteria. Source: VanderPlas, J. (2017).

the subject; thus, an appropriate contribution to the solution of this type of problems is provided.

Finally, the segmentation of the large-scale database in segments that group the fingerprints by their characteristics was proposed. After the segmentation, a single segment is selected and the search for the fingerprint to be identified would be performed in it. This model provides for an efficient response time when searching for a specific fingerprint in a very large database.

\section{BACKGROUND}

\section{Fingerprint Classification Using Orientation Field Flow Curves (OFFCs)}

Dass and Jain (2004) review the different sets of approaches that have been developed for fingerprint classification and verify that the hybrid methods developed have not been tested on large databases. The authors also point out that the classes used for classification are important. Other researchers have used four classes that did not prove to be effective for classification; therefore, the authors propose five classes to obtain better results.

According to Dass and Jain (2004), the procedure they used almost managed to determine the classification of the fingerprints with a percentage of $94.4 \%$ accuracy, so they propose to include the detection of the areas where the smallest loops originate in future works, in addition to continue taking as a basis the classification proposed by Henry (1900), which consists of: arch, right loop, left loop, arch, tentarch and whorl.

The procedure used is based on the NIST4 (National Institute of Standards and Technology) database, and the approach used is a combination of the structural, syntactic and purely mathematical approach (Watson \& Wilson, 1992).

\section{An Effective Method for Classification and Fin- gerprinting Search}

The key to the task of fingerprint image classification is features. The effectiveness of feature extraction depends on the quality of the images, the representation of the image data, the image processing models, and the evaluation of the feature extraction.

Real-time evaluation of image quality greatly improves the accuracy of the identification system. Good quality images require less pretreatment and enhancement. In contrast, poor quality images require more pretreatment and, of course, enhancement. Efficient fingerprint search requires high quality fingerprint images.

Most methods classify fingerprints into four or five classes with an accuracy level of $80 \%$ to $95 \%$. The method proposed by the authors classifies them into six classes with which an accuracy level of $97 \%$ is obtained, which shows an improvement over the previous ones (Bhuvan \& Bhattacharyya, 2009). 


\section{A Real-Time Matching System for Large Finger- print Databases}

A simpler technique is provided by Ratha, Karu, Chen, and Jain (1996): it consists of placing the images in the database as a plaintext, which is a sequence of characters with the information of each pixel. The main drawback of this method is that the scene description may be different at different times for the same image, depending on the context of the query. The authors propose reducing search space using feature extraction techniques.

A fingerprint database is characterized by a large number of records (in the order of millions). The size of the $\mathrm{FBI}$ database has grown from over 0.8 million fingerprint cards (10 fingerprints per card) in 1924 to over 114 million fingerprint cards in 1994. The storage requirements for such a large collection of images runs into 1.140 terabytes without compression. In addition, the query type of this system is expected to differ radically from other image database application domains.

The image of the same object can vary depending on its orientation, ambient light and the sensor itself. The sensed information is of a much higher dimensionality than textual information. In a digital library there are mainly three components: data capture, storage management, and search and query techniques.
According to the proposal of Ratha et al. (1996), image information is separated into its characteristics for storage in the database. Thus, all that is needed is to take a picture of a person's fingerprint and compare it with the person's own characteristics.

Poor quality images often reduce the accuracy of the system. Therefore, according to Douglas (1993), an image quality assessment is being considered at the input stage.

\section{Linear Search Model}

As seen in Figure 6, currently the fingerprint search in a large database demands too much response time when performing a linear search, even when the database is organized, so this search is timecost related.

\section{Linear Fingerprint Search}

When a fingerprint image is entered (see Figure 6), in bmp format, it is represented in a matrix whose elements are zeros and ones. A connection is then made to the database to search for this array, which has the BLOB (Large Object Binary) type.

Then the following code explains how SQLite performs a linear search record by record, and returns a list. If the item has been found, this list has a size greater than zero. Otherwise, the size is zero. This enables the user to determine when a search has been successful (see Figure 7).

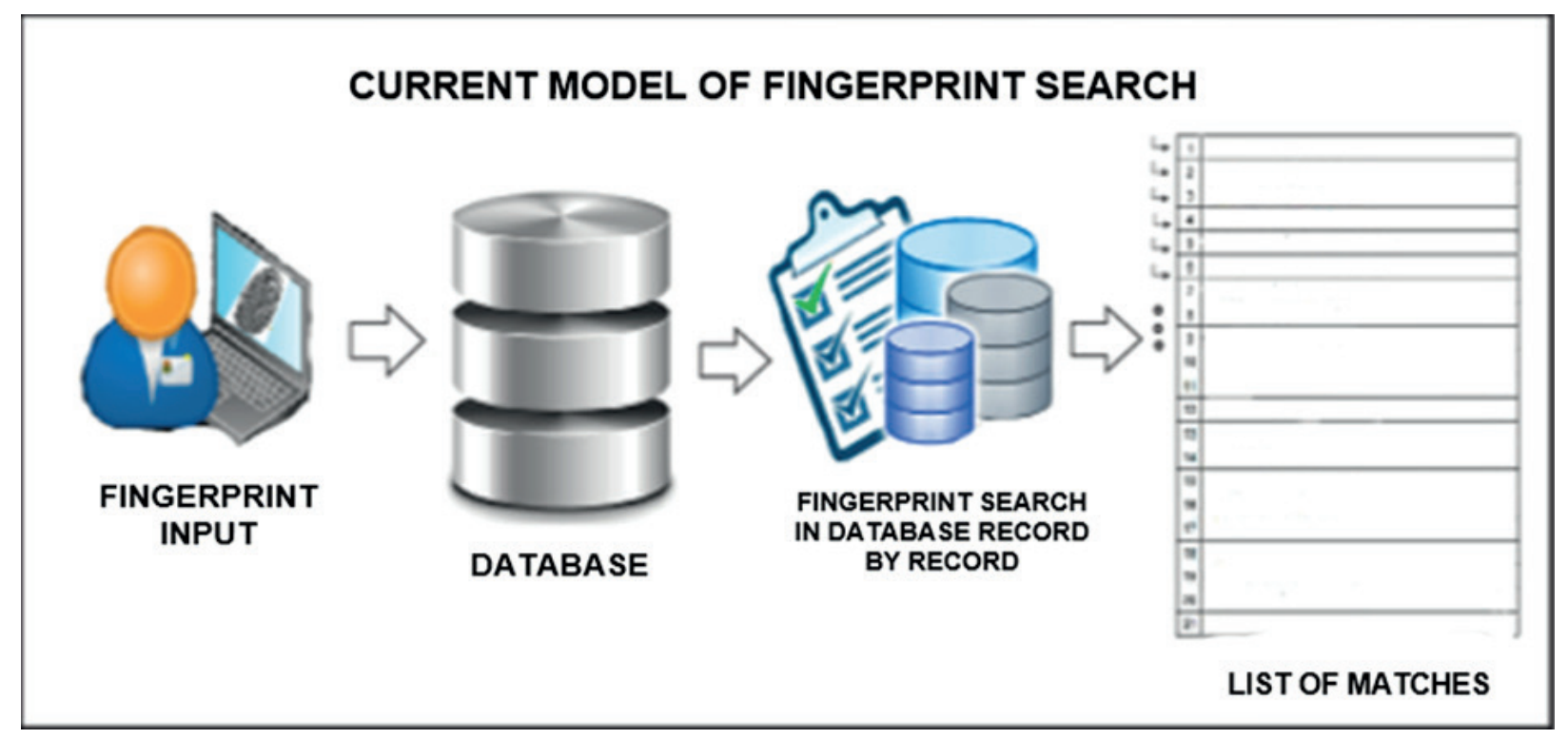

Figure 6. Current model of fingerprint search. Source: Prepared by the authors. 


\section{Proposed Model}

The proposed model segments the large database according to the characteristics of each of the fingerprints, so that the search is not performed in the entire database but in a certain segment, and thus an immediate result of the identification of the searched fingerprint is obtained, as shown in Figure 8.

First, the fingerprint of the person to be identified is entered. The computer runs the classification application for the fingerprint entered, which will return the corresponding segment number found in the database already trained for the respective search. This database contains all stored fingerprints. Searching the unsegmented database requires a very long response time which, in some cases, is essential for making a decision.

The database that stores the fingerprints is large, so when performing a linear search, it takes a considerable time to give a response, even when the database is indexed. These fingerprints have

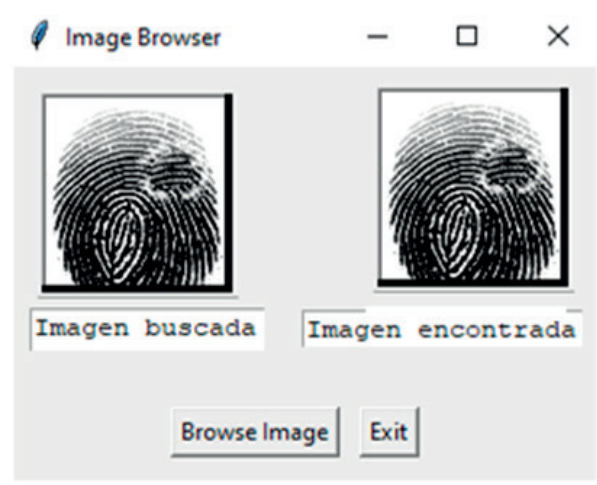

Figure 7. Fingerprint entered and fingerprint found.

Source: Prepared by the authors.

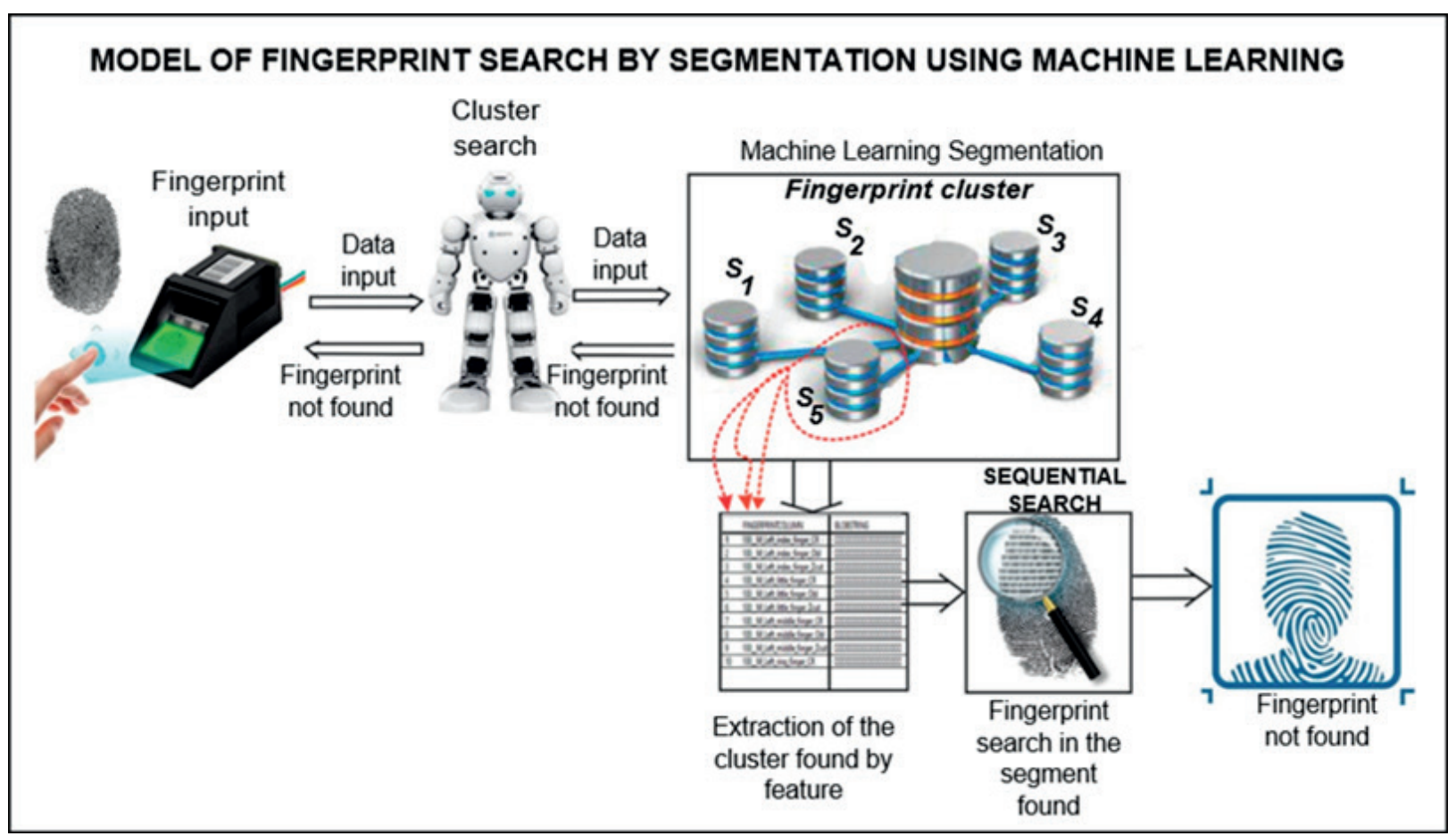

Figure 8. Model of fingerprint search in large databases.

Source: Prepared by the authors. 
certain characteristics that allow them to be classified into segments, so the search can be limited to the selected segment containing the fingerprint to be searched. Machine learning is used for the segmentation, specifically the k-means algorithm, which allows grouping the fingerprints according to the characteristics that the algorithm identifies as the closest. Using this method, the database is segmented into five clusters (segments).

When the fingerprint to be searched is entered, it is classified according to the segment number that contains it. After being placed in the selected segment, a search is performed in that segment using a discrete algorithm. Note that the search is no longer performed in the entire database, but only in the selected segment. Therefore, the searched fingerprint can be identified in an optimal time by running the search in a single segment.

\section{Functions and Models}

\section{- Non-Segmented Linear Search}

A linear search of an image in a nonsegmented database is conducted in this script to obtain the time taken by the algorithm to find the searched pair and display it in the interface.

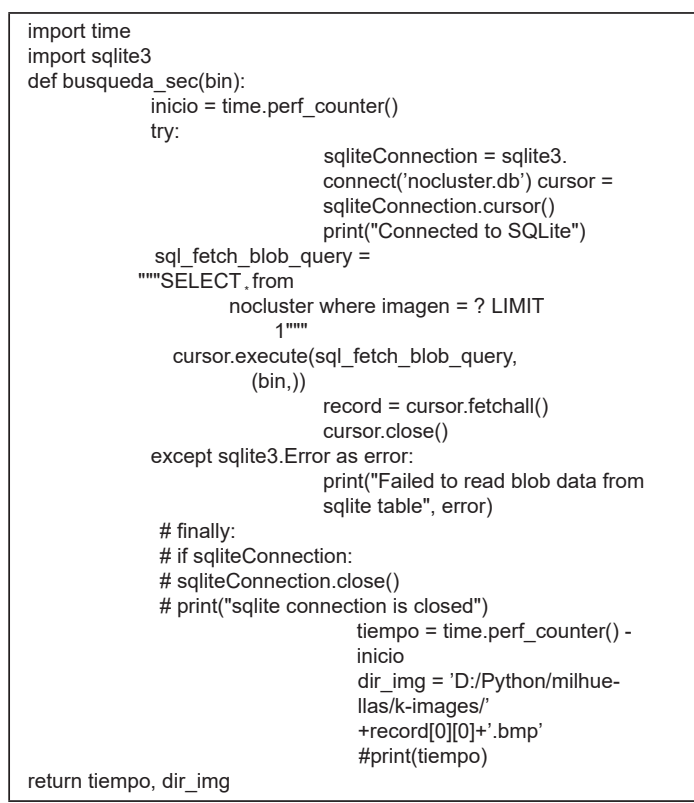

\section{- Prediction and Search}

A previously trained model is loaded and applied to predict in which cluster the image to be searched is located, then the linear search algorithm is applied in that cluster, the time of the whole process is captured and displayed in the interface.

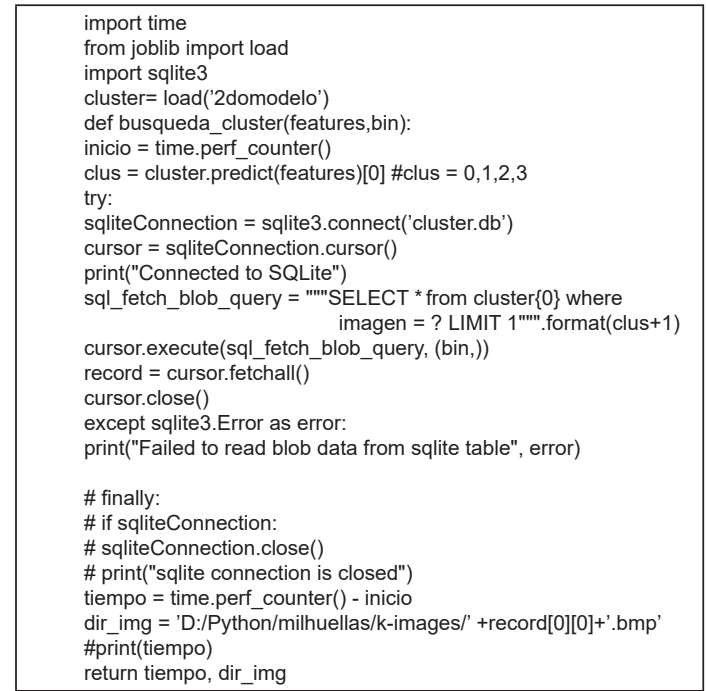

\section{- Other Necessary Functions}

Image_feature function needs InceptionV3, which is a convolutional neural network to assist in image analysis and object detection and started as a module for Googlenet.

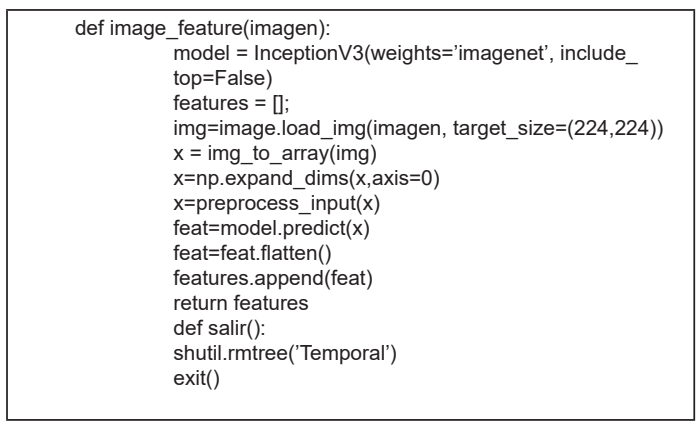

\section{Time Tests}

Finally, after the implementation of the algorithm in the program, the processing time of each search must be determined for the corresponding comparison. Fifty randomly chosen images are taken without repetition in order to analyze the evolution of the search time in relation to the position of the image in the non-clustered database. After the execution of the previously discussed algorithms, the results shown in Table 2 were obtained.

The first column describes the image position in the database, while the next two columns show the image search time in seconds using the segmented and linear algorithms, respectively.

In conclusion, we can confirm that the segmented search algorithm has advantages over the classical linear algorithm, mainly due to the following two reasons: 
Table 2. Search Time of the Proposed Algorithm.

\begin{tabular}{|c|c|c|c|}
\hline No. & $\begin{array}{l}\text { Fingerprint } \\
\text { No. }\end{array}$ & $\begin{array}{c}\text { Segmented Time } \\
\text { (sec.) }\end{array}$ & $\begin{array}{l}\text { Linear Time } \\
\text { (sec.) }\end{array}$ \\
\hline 1 & 531 & 0.004379 & 0.008464 \\
\hline 2 & 528 & 0.004228 & 0.008589 \\
\hline 3 & 517 & 0.004777 & 0.008337 \\
\hline 4 & 513 & 0.004227 & 0.008667 \\
\hline 5 & 506 & 0.003872 & 0.008317 \\
\hline 6 & 490 & 0.003828 & 0.008067 \\
\hline 7 & 486 & 0.005438 & 0.008955 \\
\hline 8 & 483 & 0.005157 & 0.010635 \\
\hline 9 & 480 & 0.004468 & 0.008513 \\
\hline 10 & 472 & 0.006281 & 0.015658 \\
\hline 11 & 444 & 0.002972 & 0.007607 \\
\hline 12 & 442 & 0.003441 & 0.007469 \\
\hline 13 & 437 & 0.003763 & 0.007042 \\
\hline 14 & 428 & 0.004522 & 0.016173 \\
\hline 15 & 408 & 0.004283 & 0.006484 \\
\hline 16 & 397 & 0.004105 & 0.008492 \\
\hline 17 & 392 & 0.004123 & 0.007803 \\
\hline 18 & 390 & 0.004025 & 0.006753 \\
\hline 19 & 377 & 0.003137 & 0.006483 \\
\hline 20 & 356 & 0.010098 & 0.014196 \\
\hline 21 & 337 & 0.003842 & 0.008346 \\
\hline 22 & 316 & 0.008645 & 0.013955 \\
\hline 23 & 312 & 0.003817 & 0.006923 \\
\hline 24 & 309 & 0.003928 & 0.005397 \\
\hline 25 & 272 & 0.003292 & 0.006387 \\
\hline
\end{tabular}

Source: Prepared by the authors.

- Linear search in a cluster takes considerably less time on average than the search time in the complete database.

- Evaluation time of an image in the classification model is short enough not to exceed the search time of the linear algorithm.

Figure 9 shows that the intersection of the linear time and segmented time lines is at point 112.5; then, according to the regression diagrams performed, it can be deduced that for a database of 537 images, the linear search time starts to increase from the image at position 113 in the unsegmented database.

\section{DISCUSSION}

Dass and Jain's (2004) approach has four main stages: first, the extraction of the orientation field for the given fingerprint image; second, generation of

\begin{tabular}{|c|c|c|c|}
\hline No. & $\begin{array}{c}\text { Fingerprint } \\
\text { No. }\end{array}$ & $\begin{array}{c}\text { Segmented } \\
\text { Time }\end{array}$ & $\begin{array}{l}\text { Linear.Time } \\
\text { (sec.) }\end{array}$ \\
\hline 26 & 268 & 0.002802 & 0.004809 \\
\hline 27 & 264 & 0.009219 & 0.008393 \\
\hline 28 & 261 & 0.003089 & 0.005612 \\
\hline 29 & 259 & 0.003477 & 0.006325 \\
\hline 30 & 247 & 0.007648 & 0.008603 \\
\hline 31 & 237 & 0.007601 & 0.009455 \\
\hline 32 & 236 & 0.009113 & 0.005527 \\
\hline 33 & 233 & 0.003252 & 0.006325 \\
\hline 34 & 222 & 0.003704 & 0.005572 \\
\hline 35 & 211 & 0.008135 & 0.010234 \\
\hline 36 & 179 & 0.003113 & 0.003579 \\
\hline 37 & 173 & 0.002846 & 0.002438 \\
\hline 38 & 163 & 0.003166 & 0.002587 \\
\hline 39 & 156 & 0.002703 & 0.002495 \\
\hline 40 & 153 & 0.002625 & 0.002485 \\
\hline 41 & 144 & 0.002265 & 0.002865 \\
\hline 42 & 138 & 0.002307 & 0.002889 \\
\hline 43 & 121 & 0.002772 & 0.001929 \\
\hline 44 & 91 & 0.005962 & 0.003999 \\
\hline 45 & 80 & 0.002847 & 0.001563 \\
\hline 46 & 78 & 0.002946 & 0.001216 \\
\hline 47 & 66 & 0.002495 & 0.001253 \\
\hline 48 & 64 & 0.002835 & 0.001167 \\
\hline 49 & 42 & 0.002091 & 0.001048 \\
\hline 50 & 9 & 0.003076 & 0.000588 \\
\hline
\end{tabular}

orientation field flow curves (OFFCs); third, labeling of each OFFC into the four classes: left and right loops, whorl and arch; and finally, an overall classification of the fingerprint image into one of the four classes based purely on mathematics (the orientation value of the fingerprint image is a vector) and using methods from differential geometry. According to Dass and Jain (2004), the procedure they used determined the classification of the fingerprints with $94.4 \%$ of accuracy.

The purpose of this paper is to propose a highly efficient search method using machine learning, which obtains a segmentation of fingerprints from a large database and groups them according to the characteristics of each fingerprint into segments. Then, a linear search algorithm is applied to one of the selected segments, that is, the one containing the fingerprint to be identified. Using this model, search 


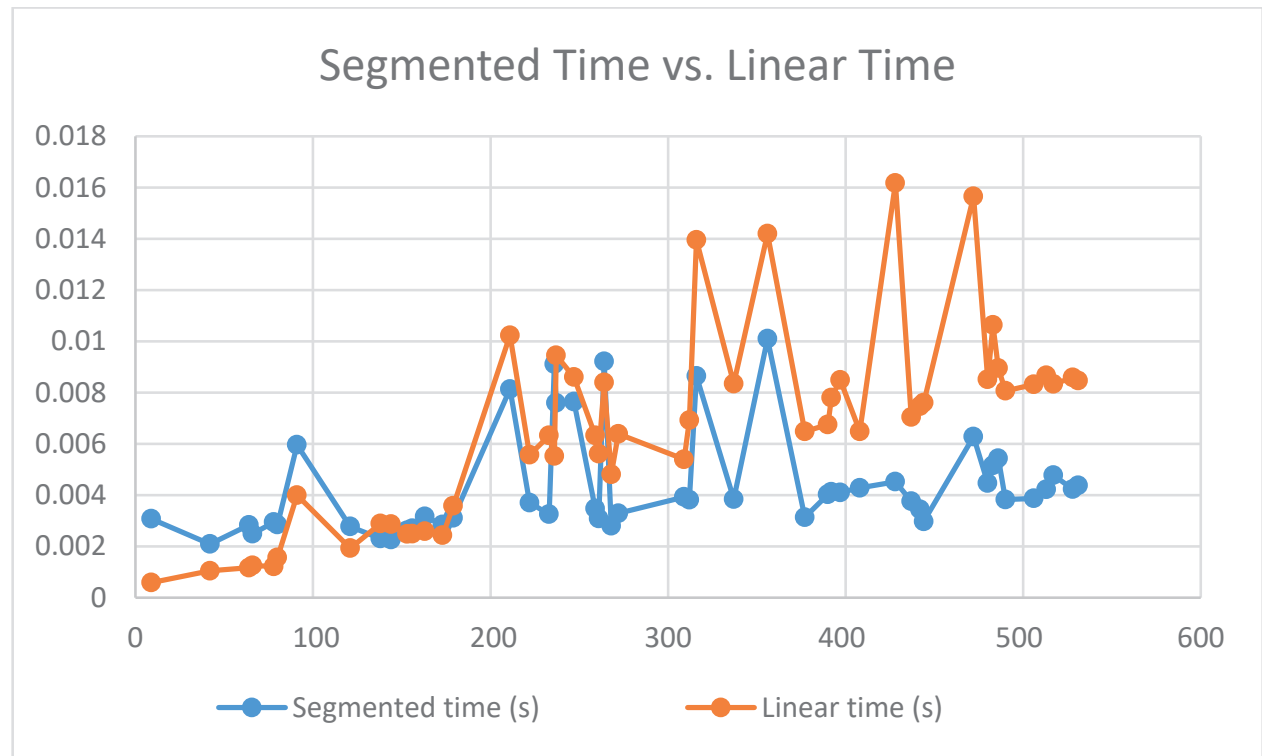

Figure 9. Time plot.

Source: Prepared by the authors.

times are minimized with a $95 \%$ confidence level. It is also demonstrated in this research that the segmented search is more efficient than performing a linear search in a large database, it is therefore more efficient than the method used by Dass and Jain (2004).

\section{CONCLUSIONS}

The main objective of this paper is to minimize search time when performing the identification of a person in a large database. After evaluating existing methods and algorithms, we conclude that machine learning allows segmenting a large database by grouping fingerprints according to their closest characteristics and then applying a linear search technique in only one selected segment to find the person's fingerprint efficiently.

This model does not search the entire database for the fingerprint, as this requires a very high response time. Instead, we propose to perform the search in only one of the segments classified by characteristics, where the searched fingerprint would be found, thus reducing search time.

\section{RECOMMENDATIONS}

For the study concerning the topic "Fingerprint search in a large database", a documentary and exhaustive methodology is suggested, using the model proposed in the topic of the research article.
Generic algorithms, which are adaptive methods that can be used to solve search and optimization problems with the sole purpose of optimizing the final results in time, are recommended when performing the segmentation.

Larger sample testing is also recommended to test the efficiency of the proposed model.

\section{REFERENCES}

[1] Bathia, S., \& Deogun, J. (1998). Conceptual Clustering in Information Retrieval. IEEE Transactions on Systems, Man and Cybernetics, Part B: Cybernetics, 28(3), 427-436.

[2] Bhuvan, M., \& Bhattacharyya, D. (2009). An Effective Fingerprint Classification and Search Method. IJCSNS International Journal of Computer Science and Network Security, 3948.

[3] Dass, S., \& Jain, A. (2004). Fingerprint Classification Using Orientation Field Flow Curves In. ICVGIP. 650 - 655.

[4] Douglas H., D. (November, 1993). Enhancement and Feature Purification of Fingerprint Images. Pattern and Recognition, 26(11), 1661-1671.

[5] Fayyad, U., Piatetsky-Shapiro, G., \& Smyth, P. (1996). From data Mining to Knowledge Discovery in Databases. American Association for Artificial Intelligence, 37-54. 
[6] Fernández, F. A. (2008). Biometric sample quality and its application to multimodad authentication systems. (Doctoral thesis). Universidad Politécnica de Madrid, Madrid.

[7] Forgy, E. (1965). Cluster analysis of multivariate data: E_ciency vs. Interpretability of classifications. Biometrics, 21, 768.

[8] Henry, E. R. (1900). Classification and Uses of Fingerprints.

[9] Kearns, M., Mansour, Y., \& Ng, A. (1997). An information-theoretic analysis of hard and soft assignment methods for clustering. (K. M. Publishers, Ed.) Proceedings of the Thirteenth Conference on Uncertanly in Artificial Intelligence, 282-293.

[10] MacQueen, J. (1967). Some methods for classification and analysis of multivariate observations. Proceedings of the fifth Berkeley symposium on mathematical statistics and probability, 1(14), 281-297.

[11] Makhoul, J., Roucos, S., \& Gish, H. (1985). Vector Quantization in Speech Coding. Proccedings of the IEEE, 73(11), 1551 - 1588.

[12] Maltoni, D., Maio, D., Jain, A., \& Prabhakar, S. (2003). Multimodal Biometric Systems. En Handbook of fingerprint recognition (págs. 233255). New York, NY: Springer.

[13] Persto S.A. de C.V. (June 15, 2020). Verificación de identidad biométrica. Retrieved from http:// www.persto.com/

[14] Pham, D., \& Prince, J. (1999). AnAdaptive Fuzzy C-Means Algorithm for Image Segmentation in the Presence of Intensity Inhomogeneities. Pattern Recognition Letters, 20(1), 57-68.
[15] Ratha, N. K., Karu, K., Chen, S., \& Jain, A. (1996). A real-time matching system for large fingerprint databases. IEEE transactions on pattern analysis and machine inteliigence, 18(8), 793-813.

[16] Scheunders, P. (1997). A comparison of clustering algorithms applied to color image quantization. Pattern Recognition Letters, 18(11-13), 1379 - 1384.

[17] Solberg, A., Taxt, T., \& Jain, A. (1996). A Markov Random Field Model for Classification of Multisource Satellite Imaginery. IEEE Transactions on Geoscience and Remote Sensing, 34(1), 100 - 113.

[18] VanderPlas, J. (2017). Python Data Science Handbook. Essential Tools for Working wit Data. Sebastopol, CA 95472, EE. UU.: O’Reilly Media, Inc.

[19] Villamizar, J. A. (1994). Procesamiento y clasificación de huellas dactilares. Lecturas Matemáticas, 15(2), 149 -165.

[20] Watson C.I., \& Wilson, C. (March, 1992). Nits 4, Special Database. National Institute of Standars and Technology.

[21] Wayman, J., Jain, A. K., Maltoni, D., \& Maio, D. (Eds.) (2005). Biometric Systems: Technology, Design and Performance Evaluation. Springer Science \& Business Media.

[22] Zúñiga, J. (n.d.). El algoritmo k-means aplicado a clasificación y procesamiento de imágenes. Retrieved July 15, 2021, from https://www. unioviedo.es/compnum/laboratorios_py/new/ kmeans.html 